\title{
An Empirical Characterisation of Speculative Pressure: A Comprehensive Panel Study Using LDV Models in High Frequency
}

\author{
Tassos G. Anastasatos \\ Loughborough University, Leicestershire \\ Ian R. Davidson \\ Loughborough University, Leicestershire
}

\begin{abstract}
This article provides a general and robust empirical examination of speculative pressure on various exchange rate regimes using an unusually large panel of monthly data for developed countries, analysed within the framework of LimitedDependent Variable (LDV) models with various innovations and extensions. In comparison to studies with lower frequency data, significant differences are found in linking crises with macroeconomic, financial and political fundamentals, despite the noise increasing tendency of higher frequency data. Considerable heterogeneity in the events surrounding crises is documented, rendering globally applicable rules for prediction and prevention inappropriate. The findings are robust to different specifications but the definition of a crisis has a bearing on its predictability.
\end{abstract}

- JEL classification: F31, C23, C25, E44, G15

- Keywords: Currency crises, Speculative pressure, Exchange rate, Devaluation, Limited-dependent variable models

\footnotetext{
*Corresponding address: Tassos G. Anastasatos, Economics Department Loughborough University Leicestershire, LE11 3TU, Tel: +44 (0) 1509 222719, Fax: +44 (0) 1509 223910, E-mail: A.Anastasatos@ lboro.ac.uk, Ian R. Davidson, Business School Loughborough University Leicestershire LE11 3TU, Tel: +44 (0) 1509 222157, Fax: +44 (0) 1509 223961, E-mail: I.R.Davidson@lboro.ac.uk
} 


\section{Introduction}

Currency crisis episodes of the last 25 years, including the Mexican default in 1982, the 1992-93 ERM crisis, the 1994 Mexican crisis and Tequila effect and the South-eastern Asia crisis in 1997-98, have inspired a renewed interest in the study of the phenomenon within the field of International Finance. Academics, policy makers and investors have a keen interest on the nature, frequency, scale and international transmission of crises, as well as their impact on the broader macroeconomy. Crashes and associated policy responses required for exchange rate defence can cause the collapse of a government's entire macroeconomic strategy. They also have consequences for investors managing exposures in high-yield currencies. In an era of financial integration and globalisation, questions of prediction, prevention and management of crises are of critical importance. This study contributes to this end by offering the most comprehensive empirical analysis of speculative attacks in developed countries. To this end, the most successful of previous attempts are combined with an approach innovative in many levels and state-of-the-art methodology. The widest selection of explanatory variables and the largest database to appear to date in this literature are employed in analysis.

A currency crisis can be defined as an occasion of extreme speculative pressure experienced by the foreign exchange market, often followed by an abrupt devaluation of the exchange rate, but sometimes repelled by the Central Bank. Several theoretical explanations attempted to describe sequences of events which can affect the dynamics in an economy, and the foreign-exchange market in particular, and motivate speculative attacks; for an overview see Flood and Marion (1998). The literature originated with the so-called "first generation" models (FGM thereafter); Agenor et al. (1992) offer a survey. Salant and Henderson (1978) utilised the model of Hotelling (1931) of exhaustible resource pricing to study attacks on a government-controlled price of gold. Krugman (1979), applied the principle to fixed exchange rates, developing the archetypal "canonical crisis model"; a refinement of this is found in Flood and Garber (1984). FGM postulate that the initial spark for a crisis is the inconsistency between rigid exchange rate targets and expansionary domestic policies. If such a policy, e.g. a steadily increasing fiscal deficit in Krugman (1979), is exogenously given and prioritised by a government, a crisis is inevitable.

"Second generation" models (SGM thereafter) occurred as an extension of the Kydland-Prescott (1977) and Barro-Gordon (1983) models of time inconsistency 
of monetary policy, perhaps the best representation being Obstfeld (1994). In those models, difficulty to defend a fixed exchange rate is a result of reduced confidence from the public in the preservation of the fixity and not of the policy conflict itself. For example, expectations of inflation, incorporated into wages, can deteriorate monetary fundamentals and hence exacerbate the impact of an adverse demand shock, which in turn enhances the government's temptation to devalue and the general expectation that this will happen. Therefore, the cost of defence depends on endogenous variables too, e.g. increases of interest rates. It follows that any equilibrium is "fragile" because expectations can be self-fulfilling and multiple equilibria are possible for the exchange rate. In this context contagion is interpreted as a vulnerability to attacks in countries with healthy fundamentals. The reason might be an erosion of competitiveness due to a depreciation of a trading partner's currency (e.g. in Gerlach and Smets, 1995). It can also be a belief by markets that countries might react in like manners if attacked, either due to structural macroeconomic similarities (e.g. in Buiter et al, 1996), or for psychological reasons.

Third generation models (TGM) focus on the interaction between currency and banking crises. Authors like Mishkin (1992, 1996), Calvo and Mentoza (1997), Caplin and Leahy (1994), used the concepts of asymmetric information, moral hazard and adverse selection to show that imperfections of financial markets, combined with implicit or explicit bailout guarantees of banks by the state, can lead to risky and excessive investment. Then, several exogenous factors can lead to a generalised financial turmoil, which is sequentially transmitted to the foreign exchange market ("twin crises"). If so, depreciations are a symptom of the boombust cycle rather than the cause of economic distress.

Despite the plethora of approaches, Rose (2001) notes that the profession has not managed yet to give clear-cut answers as to the causes of crises or indeed their precise definition. Models almost appear to resemble the idiosyncrasies of the particular wave of episodes they are designed to explain. However, Berg and Pattillo (1998) point out that, since the exchange rate is effectively an asset price, failure to explain sharp and predictable movements, like those occurring in crises, would cast doubt on the validity of the rational expectations hypothesis. The challenge is therefore firmly in the court of the empirical literature to test theoretical predictions in an unbiased and exploratory manner, while enhancing our understanding of the mechanics of currency crises.

Unfortunately, findings to date are not robust and out-of-sample prediction is 
poor, especially in higher frequencies, with noise seeming to obscure any relationships with fundamentals. This fact has given credence to perspectives claiming the predominance of market sentiment and self-fulfilling expectations. If these explanations were valid, the predictability of crises is doubtful. ${ }^{1}$ However, poor results may, at least partly, reflect the flaws of applied econometric methodologies. In addition, it may also be that crises do not show an adequate degree of resemblance to permit generalisations from previous experience, so that extraction of patterns applying to all currency crises is infeasible.

Our contribution is based on these considerations. Hence, early empirical studies like Blanco and Garber (1986), Cumby and van Wijnbergen (1989) and Goldberg (1994) cannot be used as a benchmark. These approaches draw their evidence from particular episodes, which are not necessarily representative of the entire population of attacks and devaluations. Closer to our aim is the "indicators" approach of Kaminsky et al. (1997), which monitors unusual digressions of a series of fundamentals and accordingly signals a crisis. However, the most widely acknowledged and rigorous line of analysis employs Limited-Dependent Variable (LDV) models; examples include work by Eichengreen et al. (1995,1996), Frankel and Rose (1996), and Klein and Marion (1997). We adopt this approach for its advantages explained in section 2, amongst which, its susceptibility to direct testing of the homogeneity hypothesis, an aspect neglected by previous studies.

We examine all cases of speculative pressure, irrespective of the scale or outcome, instead of focusing exclusively on extraordinary cases of either successful or failed attacks. The methodology adopted tests whether crises of different magnitude, locality and timing share the same features in terms of generating factors, irrespectively of the process of evolution. This is done with the use of appropriate specification tests and sensitivity checks, as well as with the evaluation of explanatory and predictive power of the respective general models by performance measurement techniques. Contagion of geographically or temporally adjacent crises, either causal or as a result of herding behaviour is also addressed.

A question of particular importance concerns the interval of estimation. Frankel and Rose (1995), among others, showed that the role of fundamentals is existent in the determination of the exchange rate but weakens substantially in higher frequencies. The phenomenon is attributed by Jeanne and Rose (1999) to the

${ }^{1}$ If this is the case, a zone of vulnerability could still be detected. Also, relative severity of crises in various countries could be forecasted by approximating vulnerability to a shock, like a global decrease of confidence 
presence of noise trading, an explanation which is compatible with the hypothesis of multiple equilibria in the foreign exchange market and speculative bubbles. It is possible that a combination of risk aversion and model uncertainty breaks the exchange rate arbitrage in the short-run and creates some short-run dynamics. Although it is established that volatility is higher in free floats, the argument should be valid also for the prediction of the direction and approximate timing of a realignment in a fixed regime. Therefore, the norm for empirical studies of speculative attacks has been to use quarterly or even annual data. Some produced significant relationships with various fundamentals, albeit with limited robustness of the results and mediocre predictive performance. However, low frequency estimation eliminates the usefulness of the approach as a predictive tool. Thus, the optimum data frequency should strike a balance between regular update of information, especially for rapidly changing factors, timely prediction and containment of trading noise. Furthermore, examining whether recognized longer-term relationships remain valid, weaken or are reversed in the short-run is a study in itself. For example, it could be the case that attacks occur only when misalignment of fundamentals is accumulated over an extended period.

Hence, this study uses monthly data. Short-run dynamics are addressed with the innovative utilisation of heteroskedastic and panel data extensions of the basic LDV models. If frequency-dependent fit persists though, this lends support to the speculative bubbles hypothesis or the absence of a deterministic attack-triggering threshold of misalignment. If this is the case, fundamentals work, if at all, as coordination devices for expectations. It must also be stressed that higher frequency data offer a realistic chance to capture smaller and shorter duration episodes, especially the unsuccessful ones, whose effects on indices would have faded away long before quarterly or annual figures were aggregated for publishing. Thus, we aimed in a more complete and representative sampling of all episodes, from minor repelled ones to major crashes, without discriminating according to duration and intensity. This large panel broadens the scope of this study beyond that of Frankel and Rose (1996) and Klein and Marion (1997), who focus exclusively on devaluations (defined on an ad hoc basis). This study should be considered an analysis of all occasions of speculative pressure; devaluations, as a special subset of speculative pressure, are analysed after the general case.

We chose to work with developed countries for the reason their markets are mature. Explanations based on the concepts of moral hazard and adverse selection, are tailor-made to suit the emerging Asian markets, on the presumption that 
information break-downs and herding can occur in shallow and illiquid markets. Therefore, examining the degree of applicability of such explanations in developed countries is another indirect test on the generality of any theoretical results. Developed countries also offer satisfactory data availability at monthly periodicity, allowing us to compile a large panel in order to maximise the depth of the empirical analysis.

Our results suggest that several factors are related to crises, primarily the money supply, the real exchange rate, a lack of real growth and contagion. However, significant departures in the patterns of crises' links with fundamentals are uncovered in comparison with studies in lower frequency. In addition, heterogeneity among crises is documented, according to time and place of occurrence, and success or failure of the attack. Thus, globally applicable rules for prediction and prevention are inappropriate. Findings are robust to different specifications but the definition of what constitutes a crisis affects prediction, a fact ignored by prior literature. Higher frequency augments noise.

The paper is organised as follows. In section 2 we detail the econometric methodology and data. Sections 3 and 4 contain the empirical findings, with section 3 dealing with the specifications and results for the basic binomial models and section 4 containing extensive sensitivity analysis. The conclusions and policy implications are presented in section 5 .

\section{Methodology and Data}

\section{A. The LDV Methodology}

The methodological basis for empirical testing is the non-linear LDV Models. We adopt this approach as it is capable of systematically investigating the nature of the causalities surrounding currency crises and subsequently the extent to which crises are all alike and thus predictable. The probit/logit methodology allows to treat crises as discrete extraordinary events and to summarise all underlying causalities in a single probability. This differentiation from the general study of the course of exchange rates is desirable also because not all crises end in devaluations and not all devaluations are involuntary. LDV models are not constrained by the simplistic assumptions of OLS. Finally, they permit comprehensive aggregation of all predictors, taking account of linear and non-linear correlations among them and testing of complicated econometric hypotheses, such as that of cross-time and cross- 
country constancy of coefficients. Although neglected by previous studies, this is a direct test for the homogeneity of crises hypothesis. Instability of coefficients would undermine out-of-sample prediction.

The Binary Response Model (BRM) is obtained by assuming an underlying response variable $\mathrm{y}_{\mathrm{i}}{ }^{*}$ which is defined by the linear regression relationship with a vector of explanatory variables:

$$
y_{i}^{*}=\boldsymbol{x}_{i} \beta+\varepsilon_{i}
$$

For the application at hand, $y_{i}{ }^{*}$ is a "speculative pressure" index, defined below. $y_{i}{ }^{*}$ is assumed to be latent (in our application it is actually directly observable, without this affecting the derivation of the model). We observe instead a binary variable $y$, here a "crisis" outcome defined by:

$$
\begin{cases}y_{i}=1 & \text { if } y_{i}^{*}>\tau \\ y_{l}=0 & \text { otherwise }\end{cases}
$$

where $t$ is a threshold. For BRM, the usual assumption is $\tau=0$.

Coefficients and probability of the event are estimated with ML methods. Assuming a logistic cumulative distribution of $\varepsilon_{\mathrm{i}}$ renders the logit model, and normally distributed errors the probit model. For the binomial case the two models are indistinguishable after some scaling of coefficient values, so for comparability we use the probit specification throughout.

We now turn to the definition of the speculative pressure index, $y_{i}{ }^{*}$. Identification of currency crises is a delicate task since the process appears to vary across episodes and several macroeconomic indicators are involved. Symptoms accompanying different episodes include reversals of capital inflows, bankruptcies of banks and non-financial corporations, government bailouts, repudiation of international debt, excessive volatility in all capital markets and usually sharp declines in GDPs in the aftermath of crises. Also, Meese and Rogoff (1983) and Mussa (1979) established that structural models perform poorly in measuring excess money demand and predicting the exchange rate. Hence, 'crisis' has to be approximated by invoking an ad hoc construction of 'speculative pressure'. Extending the model of Girton and Roper (1977), excess demand for foreign exchange is manifested through up to three non mutually exclusive channels, namely devaluation, sales of reserves and/ or raising of interest rates. A weighted average of some or all of these serves as the 'latent' variable $y_{i}{ }^{*}$. We will follow Eichengreen et al. $(1995,1996)$ in referring to this as the 'Exchange Market Pressure' index (EMP) and in scaling the variables 
against those of Germany, chosen as the reference country because of its post-war monetary stability. Hence,

$$
E M P_{i, t}=\left[\left(a \Delta s_{i, t}\right)+\left(\beta \Delta\left(i n t_{i, t}-i n t_{R, t}\right)\right)-\left(\gamma\left(\Delta r_{i, t}-\Delta r_{R, t}\right)\right)\right]
$$

where, $s$ is the nominal bilateral exchange rate w.r.t. the currency of the reference country (DM), int the short-term interest rate and $r$ a ratio of international non-gold reserves to monetary liquidity, usually M1. All variables are in natural logarithms, D denotes the rate of change (typically first differences), the subscript $\mathrm{R}$ denotes relative values of the reference country, and $\mathrm{a}, \mathrm{b}, \mathrm{g}$ are positive constants, inversely related to the volatility of respective elements, acting as weights.

Scaling provides some form of "standardisation" but runs the risk of rendering the data-based episode selection endogenous to any idiosyncratic shocks in the reference country, the most prominent example being the German unification. This possibility is formally tested. As an alternative, we also construct an index of the form:

$$
E M P_{i, t}=\left[\left(a \Delta s_{i, t}\right)+\left(\beta \Delta i n t_{i, t}\right)-\left(\gamma \Delta r_{i, t}\right)\right]
$$

and exchange rates are typically expressed against the U.S. dollar. Frankel and Rose (1996), inter alia, have also made this choice. This effectively sets U.S. as the reference country for the exchange rate. Most likely, given the importance of the U.S. for the global economy, events in the U.S. would, to some degree, be conveyed and added to shocks occurring to any other reference country.

Variants of both schemes are employed in our empirical analysis. Using the respective index, crisis is then defined by setting the threshold $\tau$ of (2) to be $\left(\delta \sigma_{E M P}+\mu_{E M P}\right)$, where $\sigma$ and $\mu$ are the mean and standard deviation of EMP respectively and $\delta$ a positive constant, usually 1.5 . This approach is closely associated with the spirit of theoretical models. Equally importantly, it is capable of capturing attacks on exchange regimes less rigid than pegs. However, to ensure the generality of any uncovered patterns, episodes for study should be representative of the underlying population of collapsing pegs and rapid depreciations in free floats.

Most authors weigh the components of the index so that volatilities are "equalised" and no single component dominates the index. Although plausible, this is an ad hoc practice and it could seriously affect the results obtained. Thus, our sensitivity analysis includes tests for the weighting scheme.

Nevertheless, components of the index, and especially exchange rates and reserves, also have large differences of scale and variability across countries. Furthermore, reserves are measured in U.S. dollars while M1 and M2 are measured 
in local currency which, in addition, is a different multiple of 10 of each country's currency unit in order to agree with other macroeconomic measures. Therefore, weighing each of the components of the index by a single volatility measure for all countries' data, is bound to create bias, to the extent that use of differenced data does not eliminate cross-country differences of variance. In order to avoid averaging and biases in favour of larger-scale observations, we compute countryspecific means and respective standard deviations for each of the three components of the composite index. Then these country- specific variance-standardised series are integrated in a new single index as in:

$$
E M P_{i, t}=\left[\left(s_{i, t} / 3 \sigma_{i}^{s}\right)+\left(\left(i_{i, t}-i_{G, t}\right) / 3 \sigma_{i}^{i n t}\right)-\left(\left(\% \Delta r_{i, t}-\% \Delta r_{G t}\right) / 3 \sigma_{i}{ }_{i}\right)\right]
$$

Where subscript $t$ stands for the month and i for the country. Subsequently, episodes are captured as instances in which $E M P_{i, t}$ is 1.5 or more standard deviations higher than the in-sample mean of the standardised series. This method should yield more balanced variabilities of the three components and thus signal "crisis" in a way reflecting more accurately the peculiarities of each country. It is also expected to mediate the problem of missing out predictable crises due to quoting only extreme one-month movements.

Another point of concern is the Flood and Marion (1998) critique. The Krugman (1979) model assumed a zero-maturity interest rate. However, if the interest rate is longer term and uncertainty exists, interest rates start rising and reserves start dropping before the attack. This way, the size of crisis is allocated over a number of consecutive periods. Furthermore, an attack on a peg may end with a devaluation rather than floating. If the new regime is considered viable, at least for a period longer than the maturity of the interest rate used in money demand, the devaluation should be followed by a fall of interest rates back to the level of foreign interest rates, and reserves should return to satisfy increased money demand. Thus, in the case of recurring attacks, two out of three indicators point in the wrong direction. If the above are true and provided the Krugman (1979) model is correct, selecting "crises" as one-period extreme values of the index predisposes towards crises with significant unpredictable components, in terms of correlations with informational variables. This factor may have contributed to the mediocre predictive performance of previous models.

We propose an answer to the Flood and Marion (1998) critique. If crisis jumps are somehow allocated in a number of periods before the attack, then speculative pressure can be captured more efficiently by an alternative definition of the critical value of the 'crisis index' that reflects this build up. We posit that a crisis occurs 
when a weighted average of three consecutive observations exceeds a set limit:

$$
\left\{\begin{array}{l}
\text { Index }_{i, t}=1, \text { if }\left(w_{0} E M P_{i, t}+w_{1} E M P_{i, t-1}+w_{2} E M P_{i, t-2}\right)>\delta \sigma_{E M P}+\mu_{E M P} \\
\text { Index }_{i, t}=0, \text { otherwise }
\end{array}\right.
$$

Where $w_{0}, w_{1}, w_{2}$ are positive constants with $\sum_{i=0} w_{i}=1, w_{0} \geq w_{1} \geq w_{2}$

Regressors are also lagged three periods, so that they do not carry information posterior to the initiation of crises. Thus, prediction is still a valid operation of the model. Different values of $w$ 's, are tried, in accordance to other findings of preliminary analysis. The monthly nature of data allows some optimism that this specification can capture more ably the short and medium-run dynamics of the built-up to a crisis; with quarterly or annual data this lagging construction would be useless.

The construction of the EMP index is constrained by two important data-related limitations. Firstly, Klein and Marion (1997) point out that in a world of perfect capital mobility and risk-neutrality the probability of devaluation should be given by interest rate differentials. However, several factors, such as capital controls, risk premiums, and centrally set interest rates, hinder the correspondence of interest rate differentials and expected rate of depreciation. Thus, the argument for including interest rates within the factors determining speculative pressure is questionable. Secondly, Eichengreen et al. (1996) remark that data on international reserves may not capture foreign exchange intervention efficiently since they omit or inadequately reflect factors like off-balance sheet transactions, third-party intervention, stand-by credits and foreign liabilities.

One could argue that the imposition of capital controls is an equally informative indication of mounting of speculative pressure and it could substitute reserves in the EMP index. ${ }^{2}$ In that case, reserves, as part of the money supply, could be included among regressors. Ambivalences like this in the direction of involved causalities raise methodological and economic questions and cast doubts on the correct specification of

\footnotetext{
${ }^{2}$ The quantification of capital controls, so that they can be used as an ordinal measure-component of an index, is a problem without an obvious solution. The IMF has constructed some semi-continuous indices by aggregating several categories of restrictions that central banks impose on the capital account. Choice and quantification of all these elements is dubious. Also, these series are available only for the last few years so that use with a long data set is impossible. Furthermore, Klein and Marion (1997) note that capital controls can also be circumvented by practices such as false invoicing and black market transactions.
} 
the model as a whole. Authors such as Frankel and Rose (1996) proposed the lagging of regressors by one period as a remedy to the interdependence problem; obviously this is not a theoretically justified solution and it explains little about underlying relationships.

Overall, the above points underline the problem of subjectivism in the choice of the components of the EMP index, as well as the definition of what constitutes "speculative pressure" per se. The difficulties in defining an attack, especially a failed one, and capturing it with a composite index led many authors to examine only exchange rate episodes that include devaluations. We attempt this specification too but again we let the sample pick episodes for study instead of defining them ad hoc, so that the models are still predictive. Then the criterion aims to detect only "actual" episodes and is a function of the exchange rate solely, for example:

$$
\Delta s_{i t}>k \sigma_{i}^{4 s} \text { and } \Delta s_{i t}>\lambda
$$

where $\sigma_{i}{ }^{\Delta s}$ is the standard deviation of $\Delta s$ and $\kappa, \lambda$ are positive constants. Frankel and Rose (1996) and Goldfajn and Valdes (1997) have used variants of this criterion. Its logic is to capture instances in which the devaluation is both extraordinary, after conditioning on the inflation rate, and also large enough to reduce noticeably the purchasing power of a currency. This implies a short-run alteration of the real exchange rate $e$, providing an equivalent definition of a crisis. The "crashes-only" specification gives rise to a whole sub-category of models. All aforementioned variations are applied to this family of models too and respective sensitivity tests are performed.

\section{B. Definition of the Explanatory Variables}

The choice and construction of regressors is guided by the exegeses of the theoretical models and intuition, taking in mind data availability. We employ the widest range of explanatory variables ever to have appeared in the literature, combining the successful results of previous empirical studies with innovative definitions of variables. Two broad categories can be considered: mimics of factors invoked by FGM and TGM, and sunspot variables spurring self-fulfilling crises, as in SGM. The classification is schematic as several variables have been invoked in different models.

\section{First Generation Models Regressors}

Accumulated real exchange rate (RER) misalignment. A simple RER index as a 
measure of appreciation is tried against the percentage cumulative deviation of the RER over the last 24 months to account for lagged mean reversion to an aligned (competitive) exchange rate, which is showed in empirical studies to endure up to more than two years. The finding of Klein and Marion (1997) that monthly probability of abandonment is increased by time already spent on the peg, means our measure should take account of the duration as well as the size and of the misalignment. Cumulative forms are also computed as a surplus over the pre-2year 60-month average RER, to address any significant cross-counties inequalities of accumulated misalignment in the base year and thus preserve the comparability of magnitudes over time and across countries. A prior appreciation (increase in the RER index) is expected to increase the risk of an attack, i.e. the coefficient should be positive and large, since appreciation has been depicted in the literature as a summary variable.

The current account surplus or deficit (as a percentage of GDP). Its effect is expected to be negative, but mediated by the inclusion of the RER appreciation variable. Still, it can reflect differences in the external sector policies across countries, vis-à-vis a given appreciation, as well as discrepancies in the relative price of tradeables to non-tradeables not picked up by the RER.

Growth of domestic credit (as a percentage of nominal GDP). It can be used e.g. to finance a fiscal deficit or support a problematic financial sector. The importance of this factor is inflated by the unrealistic assumption of the Krugman (1979) model that there is no access to international capital markets. In modern, open economies, its impact is expected to be positive but possibly not decisive.

Budget surplus(+) or deficit(-) expressed as a percentage of GDP: It may be a poor indicator of crises if sufficient external credit lines are available, as it is the case for many countries in the sample. Then, the central bank need not monetize a fiscal deficit and thus trigger an immediate monetary expansion. We expect a deficit to have a negative effect.

The presence of capital controls. Capital controls, reserves' disposition and interest rates are complementary or alternative tools for a Central bank defending a currency. Thus, the correlation among them is expected to be significant and the variable to be an important predictor of crises. However, its sign is uncertain. If markets perceive the restriction of certain capital transactions as a sign of difficulty of the authorities in face of capital outflows or if controls are imposed post-factum to limit panic market reactions and a recurring attack, they should appear to be positively associated with the eruption of attacks. However, if the central Bank has 
credibility and fundamentals are healthy enough, the measure may be deemed sufficient to fence short-term reversible outflows and speculators may turn their attention elsewhere. Then, the impact of the variable becomes negative. This point highlights the variable's operation as the co-ordinating device for synthesising conflicting market expectations. The constructed measure is necessarily imperfect since Central Banks also impose restrictions to the capital account which are not explicit and thus detectable in the books.

The state of the banking sector-financial crisis. Involvement of many institutional factors makes the empirical modelling of financial turmoil hard. We follow previous approaches and approximate financial turmoil by bank credit to the private sector as a percentage of GDP. The reasoning is that a rapid increase of bank credit, signifies the entrance of the economy to the boom-and-bust vicious circle since it favours the undertaking of excessive and risky investment. This is enabled by bailout guarantees of the government to banks. If a generalised run on banks occurs, this can be transmitted to the foreign exchange market. The impact of the variable is expected to be positive.

Money growth. All models predict that monetary expansion will, sooner or later, inevitably cause the price level to rise. Then, a change in the exchange rate will be required to prohibit loss of reserves and competitiveness. However, money growth can produce an abnormal and abrupt devaluation, detectable as a crisis by our composite indices, only if the rate of money creation is significantly in excess of the percentage of deprecation allowed by the exchange rate regime (zero in a fixed peg but significantly higher in managed or free floats). Otherwise, a high inflation rate, as a prominent and recognisable sign of erosion of competitiveness, can be matched by a comparable deprecation rate, which evolves in a relatively smooth and predictable pattern, without provoking attacks. We define money creation as the percentage change of real M1 or M2 (M1/P, M2/P) and we test empirically whether a narrow or broader liquidity basis is more relevant.

\section{Second Generation Models Regressors}

Growth expectations/ real growth. Both a lack of growth and poor growth expectations have been depicted as a possible motivation to abandon a system of fixed exchange rates or, more generally, to adopt a more expansionist policy. Following Persaud (1998), to the extent that the capital market is efficient, growth expectations can be approximated by the 1-month change in equity prices lagged 3 months. Both forms of the variable are expected to affect negatively the likelihood 
of an episode.

Share Prices. A nominal share prices index for each country is an alternative indirect indicator of both financial turmoil and growth expectations. A fall in the attractiveness of domestic stocks will, to a certain degree, translate into a wave of capital flights and, in a longer-term perspective, also signal weak growth prospects, thus prompting a devaluation. However, Eichengreen et al. (1995) report that on the immediate wake of an event, stock prices may rise to reflect the favourable impact of the forecasted devaluation on exports-oriented firms. Therefore, since the variable is very volatile and adjusts rapidly, use of concurrent values with higher frequency data could yield a positive coefficient in some occasions.

Electoral victory or defeat of the government. In the context of SGM, the political commitment of the government to the exchange rate regime is among fundamentals whose perceived vulnerability can trigger an attack. Changes in office are clearly chances for speculation or even herding behaviour on this commitment. Furthermore, the turns of the political circle may cause lax monetary and fiscal policies. Thus, we would expect attacks to tend to coincide with elections, unless the public expects a new government with a stricter monetary and fiscal policy. Klein and Marion (1997) note though that governments can gain credibility and reputation by maintaining a peg. Thus, as they approach the end of their administration, the corresponding cost of abandonment should increase and they cannot shift the blame for the failure to the previous government, especially when there has been an "irregular transfer of power". The variable is configured as a dummy of occurrence of election, replaced in later models by twin dummies of victory of the ruling coalition/change in office.

Degree of openness. It is approximated by (exports + imports)/GDP. A large ratio magnifies the impact of a devaluation on the aggregate price level and thus bears a greater cost in the policymaker's utility function, so it should reduce the motive to abandon a peg. On the other hand, it can increase the cost of a given appreciation of RER and hence necessitate a relief via a devaluation, so that the direction of the final causality is ambiguous.

The unemployment rate. High unemployment has been depicted by SGM as a strong motive to follow an expansionist policy of Keynesian type to stimulate demand, so it should be associated with occurrence of crises. Of course authorities could address unemployment with supply policies, such as the abolishment of minimum wage or the liberalisation of the labour market. Often markets react positively to massive lay-offs in troubled firms, viewing that as a limit to claims of labour syndicates 
and thus a containment of competitiveness erosion. However, these policies require a longer political process, so unless their global imposition is guaranteed by e.g. a neo-classical political environment, they could hardly prevent speculative attacks.

Wages. This variable lies in the core of the Obstfeld (1994) analysis; it reflects the inflationary expectations of economic agents that interact in the game-theoretic determination of equilibrium prices and thus the exchange rate. Even if actual and expected growth of the economy is high, an even higher rate of wages' growth may be deemed by the market as an erosion of competitiveness that will, sooner or later, be addressed with a devaluation. In a later model the variable is replaced by the change of the Consumer Price Index, to test whether direct measurement of total inflation is more relevant. Then, CPI is maintained along with the unemployment rate in order to embrace potential trade-offs between the two of the type of a Keynesian Phillips curve. Note however that in periods of stagflation, such as the aftermath of the two oil crises, wage reductions can lead to a weakening of demand and drag the economy into a downward spiral of negative growth.

Contagion. A dummy that takes the value of 1 if a crisis occurs at the same month in any other country within the sample (according to the particular $y$ used in each model) and 0 otherwise. Making the measure regional, as in other studies, by assigning countries to several geographic areas and signalling "1" accordingly, would have little meaning in our panel. All countries in our study are classified as developed and markets and institutions treat them as, more or less, similar. The variable should capture pure herding as well as all three aspects of "structural" contagion explained in SGM, namely: (i) trade links (competitive disadvantage from a devaluation of an important partner or competitor, as in Gerlach and Smets, 1995); (ii) macroeconomic similarities (markets speculating that countries with similar economic structure and problems will react in like manner to an attack, as in Buiter et al, 1996) and (iii) financial links (variations in investors' appetite for currency risk without any changes taking place on the fundamentals due to financiers having positions in other, devalued currencies). In interpreting results caution applies to the fact that the variable may not reflect true contagion but unobservable common shocks, i.e. "monsoonal effects".

\section{Composition of the sample}

The database assembled is the largest and most comprehensive in the crisis literature to date. It comprises 11316 monthly observations on 23 countries 
covering the 40 year period from 1960 to 2000 . The sample includes all nations classified in IMF's International Financial Statistics (IFS) under the subgroup Industrial Countries. ${ }^{3}$ This allows, inter alia, to test if the so-called safe-havens, i.e. currencies that have consistently under-performed their multilateral forward rate for a number of years, receive capital inflows when others are hit or experience contagion.

The impact of variables is explored in several time horizons, ranging from contemporaneous to one month lagged, used either jointly with the current values or by themselves, as well as on a cumulative basis. We make limited use of moving averages in order to avoid generating serial correlation. The "predictive" model using only one-period lagged variables can help to differentiate genuine leads from effects of the attack itself. It can also address the possibility of non-synchronous acquisition or processing of the relevant information from market agents.

We adopt the "exclusion window" technique applied by all existing studies. Observations immediately preceding and following the "crisis" observations are excluded in order to prevent double-counting of each episode. The same is applied to the 'tranquil' (non-crisis) periods as well, to limit imbalance in the sample, which can drown any causal relationship. Tranquil months are then used as the control group. However, the use of monthly data ends up in a significant imbalance remaining, so interpretation should be cautious not to attribute this result to shortrun speculative bubbles. In addition, exclusion windows deliberately create biases in favour of "crisis" observations; hence the models' likelihood estimates should not be interpreted as exact probabilities of an attack.

For a few indicators that are unavailable in monthly periodicity we employ their quarterly counterparts and repeat the values for 3 consecutive months; flows are apportioned across the months. The underlying assumption is that agents use the last piece of publicly available information in order to form expectations and decide their action. The reduced variability resulting from the repetition is far outweighed by the wealth of monthly updated information in a host of variables.

All major aspects of the configuration of data are tested in the Sensitivity Analysis in Section 5. Most variables enter the estimation in the form of first differences of natural logarithms.

\footnotetext{
${ }^{3}$ The data set draws from sources like the IMF, OECD, Eurostat, Keesing's Record of World Events etc. Details can be found in: http://www.lboro.ac.uk/departments/bs/research/pressure-data.html
} 


\section{Empirical Results}

A preliminary graphical analysis guided some aspects of the specification of our models and also provided an informal basis of cross-checking as well as interpreting results. Graphs revealed visible differences between periods of 5month pre- and post-crisis and tranquil spells for most variables, some of them being statistically significant. The results mostly agree with the a priori analysis but an important feature emerges: the movement of variables in the months preceding and following episodes is on average relatively low, with the possible exception of the real exchange rate. Thus, the forecast of the verbatim timing of a crisis is expected to be a difficult task. Frankel and Rose (1996) had found a similar pattern in lower frequency data. If this is a genuine attribute of the variables' behaviour, and not the result of averaging across episodes, it could mean that fundamentals, if relevant, work cumulatively or as a co-ordination device for market expectations, rather than moving swiftly to cross some deterministic threshold. This would ratify the Flood and Marion (1998) critique. Instantaneous misalignments are not enough to trigger a crisis; the pre-crisis built-up for e.g. the RER and share prices has been seen to last for more than a year on average.

Analytically, speculative attacks tend to occur more frequently in more open economies (although on average the external sector slightly shrinks close to the attack), when the real exchange rate is appreciated, share prices have plunged, the government budget is in deficit, the current account has worsened; unemployment, wages and the price level are all rising. An important feature evident from the diagrams, not seen in previous studies, is that the RER decline starts, on average, two months before the instance captured by the index as the crisis observation. Only then it returns to its long-term average, with some weak signs of over-shooting after the crisis. Since the majority of observations in the sample comes from exchange rate regimes less rigid than pegs, this finding can be interpreted as the depreciation being, on average, a gradual process rather than an one-out event. For pegs too, the Krugman (1979) postulation of a fully foreseen attack gains support; subsequent float follows the path of the shadow exchange rate, e.g. a steady decline, due to observed inflation.

To evaluate if influences resemble 'stock' variables, that is they change slowly, we have also considered a larger time window of 25 months pre- and post-crisis. All revealed regularities were reiterated and enhanced in the longer-run. In addition, unemployment continues to increase post-crisis, highlighting the recessionary effects of 
a crisis. Wages and the price level also keep rising. Thus, crises and subsequent devaluations should be viewed as a temporary relief of pressure rather than as a mechanism that would automatically correct underlying misalignments and related policy inconsistencies, which spurred those crises. The current account, real growth, the budget deficit and the share prices, all take about 15-25 months to recover to their averages. This slow and painful recovery is consistent with findings of previous studies. However, since all tranquil-period averages fall inside the 2-std deviations zone, verification should be sought from formal multivariate analysis. Furthermore, if variables work cumulatively over a prolonged period, examining their state just prior to an episode can be totally misleading.

\section{A. Pooled Time Series}

In the light of graphical analysis, the first set of models is estimated. In those, variables and the EMP index enter without reference-country standardisation. For the U.S., exchange rate will always be 1, so U.S. episodes are gleaned on the basis of deviations only on interest rates and reserves. This inefficiency is far outweighed by the value of including a country central to the global economy. Anyhow, the sample is large enough in order not to get importantly biased. Episodes are picked by the data as those observations that are at least 1.5 standard deviation above the sample's average.

Three models are estimated, using the full vector of informational variables, to test different configurations of the data. In Model 1 variables enter in natural logarithms, first differences for the variables that change quickly (RER, the stock exchange index, M1/P and openness) and third differences for slowly changing variables (credit, private loans, unemployment, wages, deficit and the current account). Third differences are suitable for variables containing some quarterly values, and they can also help in reducing seasonality. In Model 2 many variables enter in levels of natural logarithms ${ }^{4}$ instead of differences. For purposes of comparison, Model 3 uses differences of levels of observations without transformation into logarithms. Then, for Models 1 and 2, the EMP index is constructed as in (4), with weights being the inverses of the standard deviations of the respective pooled time-

\footnotetext{
${ }^{4}$ Exceptions are M1/P, openness, credit and private loans, which still enter in differences. These variables have vast differences of scale across countries so that levels are meaningless. For both Models 1 and 2, 100 is added to the current account and deficit variables so that values are non-negative and logarithms can be computed. This configuration was tested against simple differences and no substantial difference was found.
} 
series, i.e. $a=1 / \sigma^{s}, \beta=1 / \sigma^{i}$ and $\gamma=1 / \sigma^{*}$. Accordingly, for Model 3 the index used is:

$$
E M P_{i, t}=\left[\left(a \% \Delta S_{i, t}\right)+\left(\beta \Delta I_{i, t}\right)-\left(\gamma \% \Delta(R / M 1)_{i, t}\right)\right]
$$

with $a=1 / \sigma^{S}, \beta=1 / \sigma^{J}$ and $\gamma=1 / \sigma^{R M 1}$. Both indices render 8880 non-missing observations. After applying the 'exclusion window', Model 1 (2) is left with 4241 (4266) observations, of which 377 (330) are 'crisis' and the rest 'tranquillity' observations (obviously missing data preclude some of them to be used in estimation). The large number of " 1 " observations reflects our strategy to examine "experienced speculative pressure" in the broad sense and not just extraordinary crashes.

All countries had their share of speculative pressure, including "safe havens", although the latter experienced mainly repelled episodes and not crashes. Pressure exhibits some peaks, which temporally coincide with major events known to have influenced the "mature" currency markets: the crises of the dollar in late 1960's that ultimately led to the floats in 1972 and early 1973, the first and second oil crises in 1973 and 1978 respectively, the Latin America debt crisis of 1982, the U.S. interest rates rise and appreciation of the dollar in 1983-84 and the destabilisation of EMS in 1992 after the attacks on the British pound and the Italian lira. Industrial countries seem to some extent unaffected by the Mexican crisis in 1994 but more influenced by the Asian crisis of 1997-98.

Results are presented in Table 1. All three models are overall highly significant and also perform significantly better than the naïve alternative including only the constant, as shown by the LR tests at the foot of the table. Most variables are of the expected sign and many are statistically significant and sizeable. Findings exhibit robustness; it is mostly insignificant variables that have the "wrong" or alternating signs. However, indications of over-specification exist. Size and significance of variables suffers from the inclusion of collinear regressors, despite the inherent capacity of LDV models to improve their fit when new variables are added. Since models are non-linear and marginal effects depend on the size of all regressors, over-specification can also increase sensitivity.

Levels of variables seem to be less important than their dynamics, as captured by various orders of lagged differences. Even though Model 2 results are in the same direction as the rest, its performance is tangibly lower, most of the deterioration observed in variables entering in levels. By the logic of a SGM, speculators may think of certain levels of variables as sustainable. However, if a 
Table 1. Basic Pooled Data Models ${ }^{\mathrm{a}}$

\begin{tabular}{|c|c|c|c|c|c|c|c|}
\hline & $\begin{array}{l}\text { MODEL } 1 \\
\text { Obs: Dx }\end{array}$ & $\begin{array}{l}\text { MODEL } 2 \\
\text { Obs: } \mathrm{x}\end{array}$ & $\begin{array}{l}\text { MODEL } 3 \\
\text { Obs: dX }\end{array}$ & $\begin{array}{c}\text { MODEL } \\
4\end{array}$ & $\begin{array}{c}\text { MODEL } \\
5\end{array}$ & $\begin{array}{c}\text { MODEL } \\
6\end{array}$ & $\begin{array}{c}\text { MODEL } \\
6 \mathrm{~B}\end{array}$ \\
\hline Constant & $\begin{array}{c}-8.328 \\
(0.000)\end{array}$ & $\begin{array}{c}2.343 \\
(0.0191)\end{array}$ & $\begin{array}{c}-7.474 \\
(0.0000)\end{array}$ & $\begin{array}{c}-7.954 \\
(.0000)\end{array}$ & $\begin{array}{r}-4.453 \\
(.0000)\end{array}$ & $\begin{array}{l}-4.847 \\
(.0000)\end{array}$ & $\begin{array}{l}-9.938 \\
(.0000)\end{array}$ \\
\hline $\begin{array}{l}\text { Capital } \\
\text { controls }\end{array}$ & $\begin{array}{c}1.698 \\
(0.0896)\end{array}$ & $\begin{array}{c}-0.519 \\
(0.6038)\end{array}$ & $\begin{array}{l}-1.768 \\
(0.770)\end{array}$ & $\begin{array}{c}-.641 \\
(.5213)\end{array}$ & $\begin{array}{c}-.738 \\
(.4608)\end{array}$ & $\begin{array}{c}.395 \\
(.6932)\end{array}$ & $\begin{array}{l}-.091 \\
(.9278)\end{array}$ \\
\hline Election & $\begin{array}{c}-0.200 \\
(0.8412)\end{array}$ & $\begin{array}{c}0.426 \\
(0.6701)\end{array}$ & $\begin{array}{c}-0.758 \\
(0.4483)\end{array}$ & $\begin{array}{c}.204 \\
(.8387)\end{array}$ & & $\begin{array}{c}.361 \\
(.7182)\end{array}$ & $\begin{array}{l}.636 \\
(.5245)\end{array}$ \\
\hline Contagion & $\begin{array}{c}5.824 \\
(0.0000)\end{array}$ & $\begin{array}{c}6.354 \\
(0.0000)\end{array}$ & $\begin{array}{c}6.606 \\
(0.0000)\end{array}$ & $\begin{array}{c}6.984 \\
(.0000)\end{array}$ & $\begin{array}{c}2.784 \\
(.0054)\end{array}$ & $\begin{array}{c}3.582 \\
(.0003)\end{array}$ & $\begin{array}{c}.182 \\
(.8556)\end{array}$ \\
\hline $\begin{array}{l}\text { Current } \\
\text { account }\end{array}$ & $\begin{array}{c}-1.076 \\
(0.2818)\end{array}$ & $\begin{array}{c}-2.143 \\
(0.0321)\end{array}$ & $\begin{array}{c}-1.086 \\
(0.2775)\end{array}$ & $\begin{array}{c}-.813 \\
(.4161)\end{array}$ & $\begin{array}{l}-1.221 \\
(.2223)\end{array}$ & $\begin{array}{c}-1.976 \\
(.0482)\end{array}$ & $\begin{array}{l}-2.881 \\
(.0040)\end{array}$ \\
\hline M1/P & $\begin{array}{c}4.226 \\
(0.000)\end{array}$ & $\begin{array}{c}4.148 \\
(0.0000)\end{array}$ & $\begin{array}{c}0.360 \\
(0.7186)\end{array}$ & $\begin{array}{c}1.321 \\
(.1864)\end{array}$ & $\begin{array}{c}1.035 \\
(.3007)\end{array}$ & $\begin{array}{c}2.231 \\
(.0257)\end{array}$ & $\begin{array}{l}-.836 \\
(.4031)\end{array}$ \\
\hline Deficit & $\begin{array}{c}-0.389 \\
(0.6971)\end{array}$ & $\begin{array}{c}-0.742 \\
(0.4579)\end{array}$ & $\begin{array}{c}-1.716 \\
(0.0862)\end{array}$ & $\begin{array}{c}-.654 \\
(.5133)\end{array}$ & $\begin{array}{c}-.220 \\
(.8258)\end{array}$ & $\begin{array}{c}-.199 \\
(.8419)\end{array}$ & $\begin{array}{l}-1.660 \\
(.0970)\end{array}$ \\
\hline $\begin{array}{l}\text { Shares } \\
\text { index }\end{array}$ & $\begin{array}{c}-0.507 \\
(0.6119)\end{array}$ & $\begin{array}{c}-1.547 \\
(0.1218)\end{array}$ & $\begin{array}{c}0.041 \\
(0.9671)\end{array}$ & $\begin{array}{c}.115 \\
(.9082)\end{array}$ & $\begin{array}{c}.094 \\
(.9251)\end{array}$ & $\begin{array}{c}.585 \\
(.5587)\end{array}$ & $\begin{array}{l}-1.342 \\
(.1794)\end{array}$ \\
\hline $\begin{array}{l}\text { Unemp- } \\
\text { loyment }\end{array}$ & $\begin{array}{c}1.024 \\
(0.3058)\end{array}$ & $\begin{array}{c}-1.494 \\
(0.1351)\end{array}$ & $\begin{array}{c}1.143 \\
(0.2531)\end{array}$ & $\begin{array}{c}2.167 \\
(.0302)\end{array}$ & $\begin{array}{c}.816 \\
(.4147)\end{array}$ & $\begin{array}{c}-.318 \\
(.7504)\end{array}$ & $\begin{array}{c}.289 \\
(.7726)\end{array}$ \\
\hline Wages & $\begin{array}{c}0.320 \\
(0.7490)\end{array}$ & $\begin{array}{c}1.444 \\
(0.1489)\end{array}$ & $\begin{array}{c}-0.338 \\
(0.7356)\end{array}$ & $\begin{array}{l}.416 \\
(.6776)\end{array}$ & $\begin{array}{c}.163 \\
(.8704)\end{array}$ & $\begin{array}{l}.284 \\
(.7761)\end{array}$ & $\begin{array}{c}.057 \\
(.9549)\end{array}$ \\
\hline Credit & $\begin{array}{c}0.145 \\
(0.8851)\end{array}$ & $\begin{array}{c}0.374 \\
(0.7083)\end{array}$ & $\begin{array}{c}0.465 \\
(0.6421)\end{array}$ & $\begin{array}{c}1.237 \\
(.2160)\end{array}$ & $\begin{array}{c}1.142 \\
(.2537)\end{array}$ & $\begin{array}{c}-.628 \\
(.5302)\end{array}$ & $\begin{array}{c}.372 \\
(.7101)\end{array}$ \\
\hline $\begin{array}{l}\text { Private } \\
\text { loans }\end{array}$ & $\begin{array}{c}0.171 \\
(0.8640)\end{array}$ & $\begin{array}{c}0.481 \\
(0.6302)\end{array}$ & $\begin{array}{c}-0.048 \\
(0.9617)\end{array}$ & $\begin{array}{c}-.211 \\
(.8329)\end{array}$ & $\begin{array}{c}-.656 \\
(.5119)\end{array}$ & $\begin{array}{c}.686 \\
(.4926)\end{array}$ & $\begin{array}{l}-.966 \\
(.3341)\end{array}$ \\
\hline Openness & $\begin{array}{c}-1.296 \\
(0.1949)\end{array}$ & $\begin{array}{c}-2.022 \\
(0.0431)\end{array}$ & $\begin{array}{c}-0.097 \\
(0.9224)\end{array}$ & $\begin{array}{c}.621 \\
(.5348)\end{array}$ & $\begin{array}{c}1.232 \\
(.2179)\end{array}$ & $\begin{array}{c}.315 \\
(.7525)\end{array}$ & $\begin{array}{l}.972 \\
(.3311)\end{array}$ \\
\hline RER & $\begin{array}{l}-6.899 \\
(0.000)\end{array}$ & $\begin{array}{c}0.772 \\
(0.4398)\end{array}$ & $\begin{array}{l}-6.033 \\
(0.000)\end{array}$ & $\begin{array}{l}-5.856 \\
(.0000)\end{array}$ & $\begin{array}{l}-3.247 \\
(.0012)\end{array}$ & $\begin{array}{l}-4.433 \\
(.0000)\end{array}$ & $\begin{array}{l}-2.853 \\
(.0043)\end{array}$ \\
\hline $\begin{array}{l}\text { LR test } \\
\text { P-value }\end{array}$ & 0.0 & 0.0 & 0.0 & 0.0 & .002184 & 0.0 & .0270743 \\
\hline
\end{tabular}

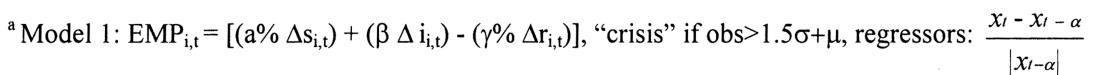

Model 2: $\mathrm{EMP}_{\mathrm{i}, \mathrm{t}}=\left[\left(\mathrm{a} \% \Delta \mathrm{s}_{\mathrm{i}, \mathrm{t}}\right)+\left(\beta \Delta \mathrm{i}_{\mathrm{i}, \mathrm{t}}\right)-\left(\gamma \% \Delta \mathrm{r}_{\mathrm{i}, \mathrm{t}}\right)\right]$, "crisis" if obs $>1.5 \sigma+\mu$, regressors: $x_{\mathrm{t}} \frac{x_{t}-x_{t}-\alpha}{\mid x_{t-\alpha \mid}}$

Model 3: $\mathrm{EMP}_{\mathrm{i}, \mathrm{t}}=\left[\left(\mathrm{a} \% \Delta \mathrm{S}_{\mathrm{i}, \mathrm{t}}\right)+\left(\beta \Delta \mathrm{I}_{\mathrm{i}, \mathrm{t}}\right)-\left(\gamma \% \Delta(\mathrm{R} / \mathrm{M} 1)_{\mathrm{i}, \mathrm{t}}\right)\right]$, "crisis" if obs $>1.5 \sigma+\mu$, regressors differences of levels.

Model 4: $\mathrm{EMP}_{\mathrm{i}, \mathrm{t}}=\left[\left(\mathrm{a} \% \Delta \mathrm{s}_{\mathrm{i}, \mathrm{t}}\right)+\left(\beta \Delta \mathrm{i}_{\mathrm{i}, \mathrm{t}}\right)-\left(\gamma \% \Delta \mathrm{r}_{\mathrm{i}, \mathrm{t}}\right)\right]$, "crisis" if obs $>1.5 \sigma+\mu$, regressorss: $\frac{x_{t}-x_{t}-\alpha}{\left|x_{t-\alpha}\right|}-\frac{g_{t}-g_{t-\alpha}}{\left|g_{t}-a\right|}$

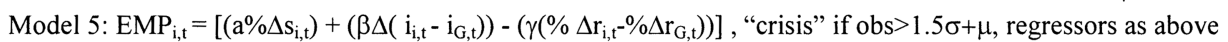

Model 6: $\mathrm{EMP}_{\mathrm{i}, \mathrm{t}}=\left[\left(\mathrm{s}_{\mathrm{i}, \mathrm{t}} / 3 \sigma_{\mathrm{i}}^{\mathrm{s}}\right)+\left(\left(\mathrm{i}_{\mathrm{i}, \mathrm{t}}-\mathrm{i}_{\mathrm{G}, \mathrm{t}}\right) / 3 \sigma_{\mathrm{i}}^{\mathrm{int}}\right)-\left(\left(\% \Delta \mathrm{r}_{\mathrm{i}, \mathrm{t}}-\% \Delta \mathrm{r}_{\mathrm{G}, \mathrm{t}}\right) / 3 \sigma_{\mathrm{i}}^{\mathrm{r}}\right)\right]$, "crisis" if obs $>1.5 \sigma+\mu$,

regressors as above.

Model 6b: as in Model 6 with regressors lagged one month.

Marginal Effects: Partial derivatives of $\left.\mathrm{E}[\mathrm{y}]=\mathrm{F}^{*}\right]=f(\mathbf{x} \boldsymbol{\beta}) \beta_{k} / \sigma$ w.r.t. the vector of characteristics,

standardised, computed at the means of the Xs. Coefficients significant at the $10 \%$ level at least are shown in

bold. Crude coefficients in left columns of each model. P-values in parentheses. 
deterioration causes the crossing of a psychological or real threshold a crisis will be spurred.

From an economic point of view, the most persistently significant variable is the proxy for contagion, a finding that reinforces in the most emphatic way the findings of Eichengreen et al. (1996). However, the contagion variable may have also captured common shocks in omitted, but influential, variables, e.g. "monsoonal effects". Monetary expansion is also a strong positive impact. Some evidence is also provided for the current account; a trade-off between the significance of the current account and the RER cannot be formally established since non-nested models' coefficients cannot be compared. By theory, a stronger impact might be expected if current account deficits had accumulated. Imposition of capital controls seems to coincide with crises, the causality's direction being still unclear. It is verified that openness and unemployment have ambivalent effects. Openness seems to reduce the motive to abandon a peg but the pattern is not stable. Evidence is tentative for unemployment, as coefficients miss significance, but a high absolute level in Model 2 decreases the likelihood of an attack, possibly being interpreted as a motive for supply policies, e.g. wage cuts. The upward trend of unemployment though, evident in Models 1 and 3, proves the inefficiency of the policy and reinstates the prospect for expansion. Some weaker evidence is provided for the wage index. It is also notable that the budget deficit variable is persistently insignificant; Frankel and Rose (1995) obtained the same finding with lower frequency data. Private loans and occurrence of elections also seem irrelevant; either variables are weakened by the inclusion of related measures, especially M1/P, or they are bad proxies of financial fragility and political developments respectively. Note though that both variables embody great noise.

The most controversial finding, in contrast with all previous evidence, is the high and persistent negative impact of the RER variable in Models 1 and 3, in which the variable enters in the form of differences. It seems as if the effect of appreciation in the short-term, if any, is to lead the market to expect even more appreciation rather than mean reversion of the RER. One could attribute this to the dynamics and the psychology of the market or even the domination of market sentiment in the shortterm. This hypothesis is enhanced by the fact that the level of RER, from Model 2, is less important than its movement. However, the graphical analysis has showed that using contemporaneous values of the variable could render a negative relation with episodes because the exchange rate had started to gradually undertake a real depreciation before the index signals a crisis. Therefore, the market may analogously 
recognise that the RER adjustment is a lengthy process. Clearly, monthly data are more able to capture the dynamics of this gradual decline than lower frequency data used before. The positive coefficient of the variable in Model 2 in which it enters in levels, is a strong indication in favour of this hypothesis, albeit inconclusive, since it is insignificant. If correct though, this further validates the Flood and Marion (1998) critique.

In the latter three models of Table 1, all variables used, both independent and dependent, enter in differences of natural logarithms scaled against respective German values. In Model 5, Index (3) serves as the latent variable with a $=1 / \sigma^{\mathrm{s}}, \beta$ $=1 / \sigma^{\mathrm{i}-\mathrm{ig}}$ and $\gamma=1 / \sigma^{\mathrm{r}-\mathrm{rg}}$; the 100 multiple of the interest rate is used. A crisis is signalled if the EMP index lies at least 1.5 standard deviations above the in-sample average. The episodes captured by this index were mostly the same as those captured by the index using unscaled data.

Inspection of data revealed that the CA/GDP and deficit/GDP variables exhibit extreme seasonality, apparently due to the particularities of the foreign trade and government budgeting processes. Scaling deteriorates the situation by adding the noise of German data on these two already noisy processes. To address the problem these two variables are constructed as differences at lag 12 rather than lag 3 in order to relieve the data from quarterly effects.

To provide a basis for comparison, Model 4 regresses the index of Model 1 against the scaled variables, which, apart from the scaling, retain the configuration of Model 1 variables. Model 5 regresses the scaled regressors ${ }^{5}$, with the corrections applied to the CA/GDP and deficit/GDP variables, against index (3), which has a single standard deviation weight for each of the index's components. Model 6 employs the same variables against the country-specific weighted index (5). Model $6 b$ is the "predictive" version of Model 6, in that all regressors have been lagged one month.

Overall, scaling against German values yielded results directly comparable to the models employing unscaled data. The basic findings are mostly repeated and retain their economic meaning, especially for variables that approach significance, and are quite robust across models. The fit of the models is better, verifying that Germany's prudence and stability helps to isolate and promote truly extraordinary movements of real macroeconomic measures over inflation-related movements.

\footnotetext{
${ }^{5}$ The dummy for election was excluded from this model and some of later ones because its limited variability, namely the absence of election in any crisis observation, was blocking the estimation of models.
} 
Hence, crises are singled out with more clarity. Despite this, the number of predicted episodes in-sample falls slightly compared to Models 1-3, especially for models employing scaled regressands. This fact shows that crises involving extreme 1-month movements may be the less predictable ones. Country-specific weights helped Model 6 to have the best fit of all models so far and also to produce the most significant coefficients. In contrast, Model 5 has fewer significant coefficients and in-sample correct calls than Model 4. Still, Model 6 has less correct calls than Model 1 that employs unscaled data.

Observed over-specification symptoms, led us to estimate models with fewer regressors. Those models exhibited less sensitivity and little disparity between simple coefficients and marginal effects, with the exception of RER. This points to a relatively small, optimal number of parameters to be estimated. However, sensitivity was not eliminated; the remainder should be attributed to structural factors and the frequency of data affecting fit. For completeness, we continue with full models.

In economic terms, the proxy of contagion and the RER variable are again the largest in size and consistently significant. 12-month differences of current account and budget deficit improve the variables' fit compared to their inclusion as 3month differences, not reported here, but they fail to improve over Models 1-3; current account is significant in Model 6. The unemployment variable records its first significantly positive sign In Model 4. The openness variable remains insignificant but it reverses its sign consistently in comparison to Models 1-3, displaying its ambivalent role. M1/P loses somehow in significance; scaling seems to deteriorate the noise of the M1/P series.

Lagging informational variables by one month, in Model $6 b$, has resulted in a dramatic drop in the fit and the in-sample correct calling of " 1 " observations. This is primarily due to the contagion and M1/P variables becoming insignificant. However, the deficit, current account and share prices variables all improve in size and significance. This phenomenon points to non-synchronous or cumulative effects of various variables, overvaluation and the money supply falling possibly to the latter case. Anyhow, the deterioration contradicts the findings of Frankel and Rose (1996), who used annual data and reported a strengthening of results when lags were introduced. This shows the vital impact of data frequency on results. Effectively, the respective models serve different purposes. Low frequency data help uncover the impact of fundamentals that work longer-term while high frequency data is more appropriate for forecasting. However, noise makes this task 
difficult.

\section{Extensions, Sensitivity Analysis and Specification Tests}

This section tests the robustness of basic results by conducting a number of perturbations in both the regressand and explanatory variables, as well as the functional form of the LDV model.

\section{A. Sensitivity Analysis: Scaling and Construction of the Index}

In Model 7, in the first column of Table 2, the level instead of the differences of variables is scaled against the respective German values and then the difference is calculated. This specification renders the likelihood of crisis a function of the existing spread between variables of each country and Germany, as well as the size of relative movements. Possible biases in cases of difference of scale between the two countries should be limited by the construction of most variables as either ratios or standardised indices. Country-specific weighted indices are utilised again; they are crucial in this specification, which allows for relative sizes to count. The largest differences in variability cross-country hold for R/M1. The specification of regressors of Models 5 and 6 is repeated. ${ }^{6}$

In order to provide a basis of comparison, Model 7 regresses the variables against index (5). Then, Model 8, employs an equivalent index constructed with data specified as above, with country-specific standard deviations as weights. As more models are fitted, it becomes apparent that basic findings about main determinants of crises remain largely unaffected across specifications of independent variables. However, the degree of success in prediction is a function of the definition of what constitutes a crisis. Not only gleaned episodes slightly vary according to the signalling rule, but also, if the index's specification does not match the tantamount of regressors, the predictive and explanatory performance of the model fall. In this particular case, Model 8 performs slightly worse than Model 7 in terms of correct calls of " 1 " observations, although identical regressors are used.

In economic terms, the basic findings from previous specifications are repeated in both models but the fit is poorer. M1/P, the real exchange rate and contagion are the stronger influences. Share prices gain importance and maintain the expected

${ }^{6}$ To facilitate the calculation of logarithms, and in this specification also to smooth out differences of scale and benchmark misalignments, multiples of 100 have been used for unemployment, wages, M1 and the price level, multiples of 10 for RER. 
Table 2. Sensitivity Analysis ${ }^{\mathrm{b}}$

\begin{tabular}{|c|c|c|c|c|c|}
\hline & Model 7 & Model 8 & Model 9 & Model 9b & Model 9c \\
\hline Constant & $\begin{array}{l}\mathbf{- 3 . 3 7 3} \\
(.0007)\end{array}$ & $\begin{array}{l}\mathbf{- 8 . 0 8 5} \\
(.0000)\end{array}$ & $\begin{array}{l}\mathbf{- 4 . 4 9 5} \\
(.0000)\end{array}$ & $\begin{array}{l}\mathbf{- 5 . 7 0 1} \\
(.0000)\end{array}$ & $\begin{array}{l}\mathbf{- 4 . 5 5 6} \\
(.0000)\end{array}$ \\
\hline Capital controls & $\begin{array}{c}.655 \\
(.5124)\end{array}$ & $\begin{array}{l}-.508 \\
(.6117)\end{array}$ & $\begin{array}{c}-1.555 \\
(.1200)\end{array}$ & $\begin{array}{c}-1.240 \\
(.2151)\end{array}$ & $\begin{array}{c}-1.681 \\
(.0927)\end{array}$ \\
\hline Election & $\begin{array}{c}.704 \\
(.4814)\end{array}$ & $\begin{array}{l}-.473 \\
(.6365)\end{array}$ & $\begin{array}{c}.902 \\
(.3668)\end{array}$ & $\begin{array}{c}.076 \\
(.9396)\end{array}$ & $\begin{array}{l}1.065 \\
(.2869)\end{array}$ \\
\hline Contagion & $\begin{array}{l}2.945 \\
(.0032)\end{array}$ & $\begin{array}{l}4.311 \\
(.0000)\end{array}$ & $\begin{array}{l}3.018 \\
(.0025)\end{array}$ & $\begin{array}{l}3.749 \\
(.0002)\end{array}$ & $\begin{array}{l}3.179 \\
(.0015)\end{array}$ \\
\hline Current account & $\begin{array}{c}.126 \\
(.8996)\end{array}$ & $\begin{array}{l}-.350 \\
(.7265)\end{array}$ & $\begin{array}{c}-1.545 \\
(.1224)\end{array}$ & $\begin{array}{c}-1.793 \\
(.0730)\end{array}$ & $\begin{array}{c}-1.572 \\
(.1159)\end{array}$ \\
\hline $\mathrm{M} 1 / \mathrm{P}$ & $\begin{array}{l}1.270 \\
(.2042)\end{array}$ & $\begin{array}{l}1.834 \\
(.0667)\end{array}$ & $\begin{array}{l}1.337 \\
(.1811)\end{array}$ & $\begin{array}{l}-.775 \\
(.4384)\end{array}$ & $\begin{array}{c}.906 \\
(.3649)\end{array}$ \\
\hline Deficit & $\begin{array}{l}-.211 \\
(.8331)\end{array}$ & $\begin{array}{c}.196 \\
(.8446)\end{array}$ & $\begin{array}{l}\mathbf{- 2 . 3 0 3} \\
(.0213)\end{array}$ & $\begin{array}{c}\mathbf{- 1 . 8 7 7} \\
(.0605)\end{array}$ & $\begin{array}{l}-2.530 \\
(.0114)\end{array}$ \\
\hline $\begin{array}{l}\text { Shares } \\
\text { index }\end{array}$ & $\begin{array}{l}-1.211 \\
(.2259)\end{array}$ & $\begin{array}{c}-1.253 \\
(.2104)\end{array}$ & $\begin{array}{l}-2.416 \\
(.0157)\end{array}$ & $\begin{array}{l}-2.411 \\
(.0159)\end{array}$ & $\begin{array}{l}-2.259 \\
(.0239)\end{array}$ \\
\hline $\begin{array}{l}\text { Unemp- } \\
\text { loyment }\end{array}$ & $\begin{array}{l}-.604 \\
(.5457)\end{array}$ & $\begin{array}{l}-.813 \\
(.4165)\end{array}$ & $\begin{array}{l}.301 \\
(.7636)\end{array}$ & $\begin{array}{l}-.276 \\
(.7828)\end{array}$ & $\begin{array}{l}-.354 \\
(.7232)\end{array}$ \\
\hline Wages & $\begin{array}{c}.243 \\
(.8082)\end{array}$ & $\begin{array}{c}.001 \\
(.9991)\end{array}$ & $\begin{array}{l}-.003 \\
(.9977)\end{array}$ & $\begin{array}{c}.216 \\
(.8294)\end{array}$ & $\begin{array}{c}.197 \\
(.8440)\end{array}$ \\
\hline Credit & $\begin{array}{l}-.146 \\
(.8837)\end{array}$ & $\begin{array}{l}-.110 \\
(.9124)\end{array}$ & $\begin{array}{c}.031 \\
(.9751)\end{array}$ & $\begin{array}{l}-.438 \\
(.6611)\end{array}$ & $\begin{array}{l}-.563 \\
(.5736)\end{array}$ \\
\hline $\begin{array}{l}\text { Private } \\
\text { loans }\end{array}$ & $\begin{array}{c}.160 \\
(.8732)\end{array}$ & $\begin{array}{l}.165 \\
(.8686)\end{array}$ & $\begin{array}{l}-.178 \\
(.8589)\end{array}$ & $\begin{array}{c}.467 \\
(.6402)\end{array}$ & $\begin{array}{c}.579 \\
(.5629)\end{array}$ \\
\hline Openness & $\begin{array}{l}-.687 \\
(.4922)\end{array}$ & $\begin{array}{c}.924 \\
(.3554)\end{array}$ & $\begin{array}{c}.074 \\
(.9412)\end{array}$ & $\begin{array}{c}.425 \\
(.6711)\end{array}$ & $\begin{array}{c}.347 \\
(.7286)\end{array}$ \\
\hline RER & $\begin{array}{l}-3.189 \\
(.0014)\end{array}$ & $\begin{array}{l}-6.081 \\
(.0000)\end{array}$ & $\begin{array}{c}-3.814 \\
(.0001)\end{array}$ & $\begin{array}{l}-2.049 \\
(.0405)\end{array}$ & $\begin{array}{l}-3.495 \\
(.0005)\end{array}$ \\
\hline $\begin{array}{l}\text { LR test } \\
\text { P-value }\end{array}$ & 0.0 & 0.0 & 0.0 & 0.00026 & 0.0 \\
\hline
\end{tabular}

${ }^{\mathrm{b}}$ Model 7: $\mathrm{EMP}_{\mathrm{i}, \mathrm{t}}=\left[\left(\mathrm{s}_{\mathrm{i}, \mathrm{t}} / 3 \sigma_{\mathrm{i}}^{\mathrm{s}}\right)+\left(\left(\mathrm{i}_{\mathrm{i}, \mathrm{t}} \mathrm{i}_{\mathrm{G}, \mathrm{t}}\right) / 3 \sigma_{\mathrm{i}}^{\mathrm{int}}\right)-\left(\left(\% \Delta \mathrm{r}_{\mathrm{i}, \mathrm{t}}-\% \Delta \mathrm{r}_{\mathrm{G}, \mathrm{t}}\right) / 3 \sigma_{\mathrm{i}}^{\mathrm{r}}\right)\right]$, "crisis" if obs $>1.5 \sigma+\mu$, regressorss: $\frac{v_{t}-v_{t-1}}{\left|v_{t-1}\right|}$, where $\mathrm{v}_{\mathrm{t}}=\mathrm{x}_{\mathrm{t}}-\mathrm{g}_{\mathrm{t}}$

Model 8: $\operatorname{EMP}_{\mathrm{i}, \mathrm{t}}=\left[\left(\mathrm{s}_{\mathrm{v}} / 3 \sigma_{\mathrm{i}, \mathrm{t}}^{\mathrm{s}}\right)+\left(\right.\right.$ int $\left.\left._{\mathrm{v}} / 3 \sigma_{\mathrm{i}, \mathrm{t}}^{\mathrm{int}}\right)-\left(\mathrm{r}_{\mathrm{v}} / 3 \sigma_{\mathrm{i}, \mathrm{t}}^{\mathrm{r}}\right)\right]$, "crisis" if obs $>1.5 \sigma+\mu$, regressors as above

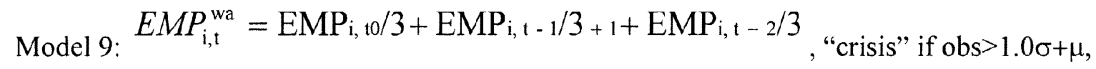

regressorss: $\frac{x_{t}-x_{t-\alpha}}{\left|x_{t-\alpha}\right|}-\frac{g_{t}-g_{t-\alpha}}{\left|g_{t-a}\right|}$, lagged 3 months (contemporaneous to signalling)

Model 9b: as Model 9, regressors lagged 4 months.

Model 9c: as Model 9, regressors arithmetic averages of contemporaneous and lagged.

Marginal Effects: Partial derivatives of $\mathrm{E}[\mathrm{y}]=\mathrm{F}\left[{ }^{*}\right]=f(\mathbf{x} \beta) \beta_{k} / \sigma$ w.r.t. the vector of characteristics,

standardised, computed at the means of the Xs. Coefficients significant at the $10 \%$ level at least are shown in bold. $\mathrm{P}$-values in parentheses, i.e. $\mathrm{P}[|\mathrm{Z}|>\mathrm{z}]$. 
sign but remain insignificant. More than in previous models, signs of nonlinearities and over-specification are evident; insignificant regressors keep alternating sign and they, overall, seem irrelevant. Thus, it seems that, with the possible exception of the share prices, the timing of episodes is determined by dynamics of variables rather than the existing spread with a reference country. To support this view, we estimated a model using regressors entered in levels. Again, as in Model 2, both the fit and correct in-sample classification of episodes deteriorated, with the exception of the current account variable which strengthened.

Next, the innovation addressing the Flood and Marion (1998) critique is applied. We construct index (6) as a weighted average of three consecutive observations of the simple index, guided by the findings of the graphical analysis that, on average, crisis jumps are allocated in roughly a period of three months before the attack. The optimisation of the selection of episodes, pursued by targeting episodes that evolve gradually and can be missed out by the one-month movement rule, comes at the risk of losing some minor episodes whose effects fade out quickly. This risk compares favourably to using lower frequency data with the standard index. Model 9 uses the index (6) with equal weights $\mathrm{w}_{\mathrm{i}}$ and an 1 standard deviation countryspecific threshold; lowering of the threshold is necessitated by the more uniform character of the index that leaves fewer episodes for study. Still, indices glean 277 episodes for Model 9 and 278 for Model 9b, in comparison to 373 for Model 6. Regressors are accordingly lagged 3 periods and they enter in the same configuration as in Model 6. Model $9 b$ is the "predictive" version with regressors lagged 4 periods. Lagging helps in capturing the built-up of the crisis, as well as its culmination, and in excluding post-crisis information from regressors. Model $9 c$ allows for contemporaneous and lagged variables to work simultaneously; regressors are constructed as arithmetic averages for preserving degrees of freedom. Share prices react rapidly, thus they enter at lag 4 in all Models $9,9 \mathrm{~b}$ and $9 c$ in order to avoid counting crisis effects in the variable.

Overall, the fit of the models improves noticeably over Model 6, the best one being Model 9. This is a strong indication that our innovation leads to the detection of episodes with more fundamentals-related components. Still, the models' insample predictive ability is low, indeed slightly lower than that of Model 6. To this end, the Flood and Marion (1998) critique that lump-sum deviation rules miss out crises with predictable components is not supported by the data. Crises that evolve gradually are not necessarily more predictable in respect to their relation with given fundamentals. This fact, although worrying, is no surprise, considering the idle 
movement of most fundamentals around crises and the noise in higher frequency data. Thus, we should not expect a dramatic increase of the percentage of correct calls under any specification.

In economic terms, contagion and RER remain strong but M1/P loses its significance. The impressive improvement of the stock prices, deficit, and current account variables, verifies that, especially the latter two, have an impact of a longer-term nature. Also, capital controls become significant but with the opposite sign than in Model 1, showing that their impact is a function of the kind of episodes that are predominantly captured by each index. Apparently, index (6) provides sufficient time margin for excluding cases of post-factum imposition and recurring attacks. Lastly, evidence that occurrence of elections affects likelihood of crisis remains very weak. The "predictive" version has somehow worse fit but less so than in previous models. The use of contemporaneous and lagged variables simultaneously does not alter results notably. ${ }^{7}$

\section{B. Sensitivity Analysis: Specification of Informational Variables}

The specification of informational variables was also altered. The 3-month change in the Stock Index, lagged one month, replaced the single share prices index as a proxy for growth expectations. Also, real growth was added, calculated as difference at lag 12 of real GDP to reduce seasonality. The binary variable for

\footnotetext{
${ }^{7}$ Additional sensitivity tests were conducted. We tested for a structural break in the point of unification of Germany in 1989. The two models estimated on the sub-samples differed substantially amongst themselves, also having a fit importantly better than Model 6, more significant coefficients and insample correct calls. Recent crises seem more affected by the increasingly interdependent global economic environment, while episodes following the collapse of Bretton-Woods are primarily driven by domestic imbalances. In the cross-section dimension, a model was estimated on "safe havens", namely the Austrian Schilling, the Belgian Franc, the German Deutschemark, and the Dutch Guilder (all four now in the Euro zone); the U.S. Dollar, the Japanese Yen and the Swiss Franc. This outperformed all previous models in in-sample correct calls (above 50\%) and in fit. Crises in "safe havens" rely more on domestic fundamentals and importance of contagion falls. The model estimated on remaining countries yielded the most significant coefficients. These results contradict the Eichengreen et al. (1996) finding of uniform across-time causalities, based on contagion. If various episodes are dissimilar, estimation on large samples may result in averaging and, thus, mediocre performance.

Then, we tested whether results are a function of the threshold used to signal a crisis. Variants of Model 6 with 1.75 and 1.25 sd thresholds did not crucially challenge basic findings. The tendency is, the broader the range of episodes captured, the poorer the fit of models. Finally, we tested the weighting scheme. In a model with country-specific EMP index we doubled the weight of the exchange rate in the index; results are robust to the modification. Subsequently, reverting to a model that utilises the basic EMP index, we tried removing weighting altogether. Then, the index is dominated by changes in reserves, which happen to have the greater variance, and secondarily interest rates, effectively minimising the role of actual devaluations in signalling episodes. Results were in the same direction but coefficients' sizes were somehow affected.
} 
election was replaced by two dummies, one for victory of the ruling coalition and one for government defeat and change in office. The latter also includes instances of irregular and violent falls of regimes and regimental change. The $1^{\text {st }}$ difference of real M2 (M2/P) replaced M1/P; for some countries which employ national definitions of monetary bases or M2 is unavailable, measures closest to the M2 were used, in a couple of cases M3. Finally, inflation replaced wages for a direct appraisal of erosion of competitiveness. In order to limit over-specification and collinearity, private loans and credit variables, both consistently insignificant in previous specifications, were omitted. The new model improved over the previous specification both in terms of significance and correct calls but repeated the main causalities uncovered before. The inflation variable performs better than wages and it is positive and significant. Victory of the ruling coalition seems to be interpreted as bad news on average but the variable does not reach significance so the finding is inconclusive. The same holds for real growth, which retains the expected sign. The improvement is partially counterbalanced by the mediocre performance of the $\mathrm{M} 2 / \mathrm{P}$ variable. It seems that, for the purpose of spurring a crisis, the notion of expansion is contained in very liquid monetary assets. When $\mathrm{M} 1 / \mathrm{P}$ is put back in the model, its performance improves further. Nevertheless, the model does not escape the rule of relatively low predictive ability that characterised most models so far.

\section{Cumulative Influences}

This section addresses two major questions that prevailed from prior models and the graphical analysis. Firstly, we test whether economic variables have a cumulative effect to the likelihood of a currency crisis. This is crucially connected with the validation of theoretical models, which assert that crises are not spurred by momentary extraordinary deviations but are rather the culmination of a long lasting process of inconsistent domestic policies. It could also be that some variables work long before an attack. Secondly, accumulation can address the hypothesis of lagged mean reversion to aligned (i.e. competitive) real exchange rates. Considering the negative sign of the RER coefficient when contemporaneous or 1-month lagged values are used and the pre-crisis appreciation revealed in graphs, we would expect the variable to have a positive impact on the likelihood of an episode if sufficient appreciation has accumulated in the ulterior past.

For maximum objectiveness of uncovered causalities, and since longer-term relations are studied, Model 10 utilises the crisis index of (6), with an 1-standard 
deviation threshold. Subsequently, cumulative variables are constructed from data scaled against Germany. To provide a basis of comparison Model 11 employs cumulated variables constructed by unscaled data and the index (4) of Model 1 as the dependent variable. As for the selection of informational variables, both Models 10 and 11 utilise the slightly more effective alternative set of regressors.

Special provision was taken for the RER, as previous models suggested that, not only size and duration of existing appreciation is important, but also sufficient lags have to be added in order not to capture the first stages of the fall in the cumulative variable. Many definitions have been tried, yielding comparable results. The RER variable used in Model 10 is the 24-month cumulative deviation of the logarithmic level of the RER with a 6-months lag, monthly readjusted. The RER variable used in Model 11 is the 24-month cumulative deviation of the first differences of the logarithmic RER with a 6-months lag, monthly readjusted. Also, 2-year cumulative values, monthly readjusted, replace the concurrent values of the following variables: the current account and budget deficit, both as a percentage of nominal GDP, the degree of openness, growth expectations and real growth. For unemployment, inflation and real money supply, the cumulative values were calculated on levels scaled against Germany. These variables exhibit strong seasonality due to the monthly frequency, so that accumulating first differences would be a rather meaningless averaging.

Results are exhibited in the first two columns of Table 3. The most important finding obviously is that the RER variable obtains now the positive sign in both its level and its dynamics. Accumulated appreciation of sufficient size and duration is a significant predictor of crises. It can be said that this result validates the lagged mean-reversion hypothesis, that had gained credibility from findings of previous studies, although in the short-run data reflect a steady-as-going expectation of the markets. In general, the two models have directly comparable features, sketching a rather more robust and holistic picture of longer-term causalities, which is closer to theoretical explanations. Although predictability does not improve, more variables turn significant and even insignificant regressors tend to have the expected sign; fit does not fall when lagging cumulative regressors by one period. It is notable that lack of real growth is more important in the longer-term perspective.

\section{Devaluation-only events}

We now turn to the estimation of models concerned exclusively with episodes involving abrupt and sizeable devaluations of the exchange rate and not with 
Table $3^{\mathrm{c}}$.

\begin{tabular}{|c|c|c|c|c|c|}
\hline & Model 10 & Model 11 & Model 12 & Model 12b & Model 13 \\
\hline \multirow{2}{*}{ Constant } & -1.746 & -.715 & -4.720 & -2.772 & -2.131 \\
\hline & (.0809) & $(.4747)$ & $(.0000)$ & $(.0056)$ & $(.0331)$ \\
\hline \multirow{2}{*}{$\begin{array}{l}\text { Capital } \\
\text { controls }\end{array}$} & -2.135 & -.151 & -2.167 & -2.576 & -1.855 \\
\hline & $(.0328)$ & $(.8797)$ & $(.0302)$ & $(.0100)$ & $(.0635)$ \\
\hline Election & & & $\begin{array}{c}1.200 \\
(.2301)\end{array}$ & $\begin{array}{l}2.142 \\
(.0322)\end{array}$ & \\
\hline Government & 1.918 & .709 & & & \\
\hline Victory & $(.0551)$ & $(.4780)$ & & & \\
\hline Government & 1.045 & & & & \\
\hline Defeat & $(.2962)$ & & & & \\
\hline \multirow{2}{*}{ Contagion } & 1.657 & 4.604 & 1.892 & 1.070 & 2.173 \\
\hline & $(.0981)$ & $(.0000)$ & $(.0585)$ & $(.2846)$ & $(.0298)$ \\
\hline \multirow{2}{*}{$\begin{array}{l}\text { Current } \\
\text { account }\end{array}$} & -1.653 & -.695 & -.810 & -1.267 & -1.948 \\
\hline & $(.0983)$ & $(.4872)$ & $(.4181)$ & $(.2050)$ & $(.0514)$ \\
\hline \multirow{2}{*}{ Inflation } & .109 & .270 & & & 1.269 \\
\hline & $(.9130)$ & $(.7868)$ & & & $(.2044)$ \\
\hline \multirow{2}{*}{$\mathrm{M} 1 / \mathrm{P}$} & .573 & .508 & 1.761 & 1.305 & 1.919 \\
\hline & $(.5663)$ & (.6114) & $(.0782)$ & $(.1917)$ & (.0549) \\
\hline Budget & .299 & .048 & -.598 & -1.372 & 986 \\
\hline Deficit & $(.7653)$ & (.9620) & (.5498) & $(.1699)$ & $(.3549)$ \\
\hline \multirow{2}{*}{ growth expectations } & .595 & -1.719 & -.719 & .253 & .014 \\
\hline & $(.5522)$ & $(.0856)$ & $(.4721)$ & $(.8002)$ & (.9890) \\
\hline Real & -1.795 & -1.883 & & & -1.682 \\
\hline Growth & $(.0727)$ & (.0598) & & & $(.0926)$ \\
\hline \multirow{2}{*}{ Openness } & .679 & -2.063 & & & -1.589 \\
\hline & $(.4969)$ & $(.0391)$ & & & $(.1120)$ \\
\hline \multirow{2}{*}{ Unemploy-ment } & 1.981 & 1.765 & .479 & -.001 & 2.032 \\
\hline & $(.0476)$ & $(.0776)$ & (.6319) & (.9990) & $(.0421)$ \\
\hline \multirow{2}{*}{ RER } & 1.704 & 1.906 & -4.634 & -2.833 & 2.003 \\
\hline & (.0972) & $(.0567)$ & $(.0000)$ & $(.0046)$ & $(.0456)$ \\
\hline \multirow{2}{*}{ Wages } & & & -.656 & -.586 & \\
\hline & & & $(.5119)$ & $(.5581)$ & \\
\hline \multirow{2}{*}{ Credit } & & & -.985 & -.893 & \\
\hline & & & (.3248) & $(.3442)$ & \\
\hline \multirow{2}{*}{$\begin{array}{l}\text { Private } \\
\text { loans }\end{array}$} & & & -.218 & .000 & \\
\hline & & & $(.8271)$ & (.9998) & \\
\hline Openness & & & $\begin{array}{l}-.621 \\
(.5344)\end{array}$ & $\begin{array}{l}-.668 \\
(.5043)\end{array}$ & \\
\hline AIC & 0.253753 & 0.406610 & 0.287055 & 0.212487 & 0.417276 \\
\hline $\begin{array}{l}\text { LR test } \\
\text { P-value }\end{array}$ & .00043 & 0.0 & 0.0 & 0.0 & 0.0 \\
\hline
\end{tabular}

P-value

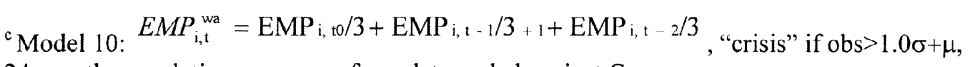

24-month cumulative regressors from data scaled against Germany.

Model 11: $\mathrm{EMP}_{\mathrm{i}, \mathrm{t}}=\left[\left(\mathrm{a} \% \Delta \mathrm{s}_{\mathrm{i}, \mathrm{t}}\right)+\left(\beta \Delta \mathrm{i}_{\mathrm{i}, \mathrm{t}}\right)-\left(\gamma \% \Delta \mathrm{r}_{\mathrm{i}, \mathrm{t}}\right)\right]$, "crisis" if obs $>1.5 \sigma+\mu$,

24-month cumulative regressors from unscaled data

Model 12: Captures devaluations only: $\left\{\begin{array}{l}\text { Index }=1 \\ \text { ind } y_{i t}>\bar{y}_{i t}+1.2 \sigma i \text { and }\left(y_{i t}-y_{i(t-1)}\right) / y_{i(t-1)}>10 \%\end{array}\right.$

regressors from data scaled against Germany.

Model 12b: Captures devaluations only, stricter criterion

Model 13: Captures devaluations only, cumulative regressors

Marginal Effects: Partial derivatives of $\left.\mathrm{E}[\mathrm{y}]=\mathrm{F}^{*}{ }^{*}\right]=f(\mathbf{x} \beta) \beta_{k} / \sigma$ w.r.t. the vector of characteristics,

standardised, computed at the means of the Xs. Coefficients significant at the $10 \%$ level at least are

shown in bold. P-values in parentheses. 
repelled speculative pressure. The basis of analysis is Model 12 in the $3^{\text {rd }}$ column of Table 3. It employs a prototype definition of a currency episode. Esquivel and Larrain (1998) define crises as instances of short-run real devaluation, on the grounds that a devaluation episode should be intense enough to leave its trace in the RER. However, this explanation is based on the short-term violation of the PPP hypothesis of which no evidence is provided. Furthermore, this definition can potentially exclude smaller, ephemeral episodes that their effect on RER was exhausted before final data were aggregated and published. Finally, this specification deprives the model from the course of the RER that proved to be one of the most significant explanatory variables. Thus, this study employs the natural benchmark, to glean from the data episodes of sizeable and abrupt devaluation of the nominal exchange rate. Variables use data scaled against German values in the form of first differences of natural logarithms, so the regressand employs the DM cross exchange rate. Nominal exchange rates can have vast differences of scale, even when written in natural logarithms. Thus, we calculate once again country-specific means and deviations from them. Then, in accordance to the logic described in section 2.1, the empirical rule for the detection of a " 1 " observation imposes the satisfaction of $t w o$ criteria:

$$
\left\{\begin{array}{l}
\text { Index }=1 \text { if } y_{i t}>\bar{y}_{i t}+1.2 \sigma_{i} \text { and }\left(y_{t i}-y_{i(t-1)}\right) / y_{i(t-1)}>10 \% \\
\text { Index }=0 \text { if otherwise }
\end{array}\right.
$$

where $\bar{y}_{i t}$ is the country-specific mean and $\sigma_{i}$ is the country-specific standard deviation of the logarithm of the nominal exchange rate respectively. Another version is estimated, Model $12 b$, which employs a rule stricter as for the relative change of exchange rate and more relaxed as for its absolute size, for gleaning devaluation episodes. "1" observations are defined as the ones for which:

$$
\left\{\begin{array}{l}
\text { Inde } x=1 \text { if } y_{i t}>\bar{y}_{i t}+1.5 \sigma_{i} \text { and }\left(y_{t i}-y_{i(t-1)}\right) / y_{i(t-1)}>4 \% \\
\text { Index }=0 \text { if otherwise }
\end{array}\right.
$$

The fit of the models as evaluated by AIC is similar to Model 6 but the models are not directly comparable since captured episodes differ significantly. Again, the stricter the signalling rule, the better the performance of models. The predictive 
ability is greatly enhanced, in terms of correct in-sample calls of episodes. This verifies findings of previous studies that actual devaluations are easier to explain and predict than more subtle cases of repelled attacks. Although the main patterns, observed in previous models employing EMP indices, are repeated, devaluations seem to be governed by more profound, and thus more detectable, imbalances. The course of the RER, monetary expansion, but also external sector imbalances are the main driving forces of devaluation. Contagion is still very relevant although it loses somehow in importance; capital controls are a significant deterrent, more so now that repelled attacks have been excluded.

Model 13 proceeds in a prototype way to explain devaluations in terms of the cumulative explanatory variables. Initial variables again are entered in data scaled against German values and, based on them, the cumulative values are formulated as in Models 10-11. The only difference is the share index (growth expectations), which is also lagged, similarly to the RER index, to account for the variable's rapid reaction. The regressand is that of Model 12. Findings closely resemble those of Models10-11 but appear enhanced. AIC suggests, for Model 13, fit comparable to Model 11; this is probably an underestimation, caused by the relatively small sample size, since accumulation costs many lost degrees of freedom. However, the in-sample predictive ability is superior. This confirms the similar finding of Model 12. Contagion, current account, capital controls, unemployment, real growth and $\mathrm{M} 1 / \mathrm{P}$, are all significant explanatory factors of devaluation with the expected signs. In contrast to Models 10-11, M1/P becomes significant in this model. This shows that relationships described by monetary models were diluted by the inclusion of less dramatic, failed attacks.

\section{E. Heteroskedasticity and Random Effects}

Throughout the literature the possibility of heteroskedasticity was overlooked, even when lengthy panels were assembled. However, this can result in inconsistent as well as inefficient estimators. Heteroskedastic disturbances are even more likely when data of higher frequency is used. In this study, we formally test for heteroskedasticity in the models and, when the homoskedasticity hypothesis is rejected, heteroskedastic binary Probits are estimated.

Firstly, we test the hypothesis of homoskedasticity against the specification of the Harvey (1976) general model that allows for multiplicative hetoscedasticity. The statistic used is an LM test distributed as $\chi^{2}$ with degrees of freedom equal to the number of variables entering the scedastic function; all regressors were entered, 
constant excluded by definition. We have been able to reject the hypothesis of homoskedasticity for all models in a convincing and robust manner at the $97.5 \%$ level. Interestingly, the largest test value was recorded for Model 10, with the cumulative values.

Subsequently, heteroskedastic counterparts of univariate probit models were estimated. The Harvey (1976) general model was preferred over simple heteroskedastic models since it can accommodate various forms of heteroskedasticity and it can also address a more general functional form problem. Since estimation involves a highly nonlinear function that increases variances, the inclusion of the variance terms dramatically exacerbates the already problematic over-specification. Thus, inclusion of all variables into the scedastic function prohibits convergence. Instead, we select the variables with sizeable standardised variance terms that approach significance, up to the extent that allows convergence, and re-estimate the heteroskedastic model.

Results indicated that especially marginal effects, but also simple coefficients, are considerably smaller for these models, and standard errors increase, compared to the respective of the simple probits. Contrary to intuition, this is an indication that the heteroskedastic specification is important and it succeeds in accounting for non-linearities in the conditional mean and heteroskedasticity. The imperfect consistence of the simple probit models with the observed data and the capacity of the Harvey (1976) model to address a more general functional form problem, mean we would expect to see heteroskedastic models rather weakly identified by that data. Especially variables that enter the skedastic function lose in size and significance, sometimes they even alter sign. The phenomenon is more evident for cumulative variables that had limited sizes even from the simple models. Large errors also affirm to some form of multicollinearity among regressors.

Nevertheless, the heteroskedastic models do improve over their simple univariate counterparts. While main features remain essentially unchanged, apart from the aforementioned added sensitivity, and AIC records only moderate improvements in fit, the predictive ability of the models improves noticeably over the equivalent simple models.

We also estimated panel data versions of the models. The data is arranged in 492 groups of 23-country observations, each corresponding to a single month, and month-specific random effects were estimated in order to investigate and analyse improvement in performance. We applied the Butler and Moffitt (1982) specification of the random effects equicorrelated model for panel data. 
The plethora of both coefficients and groups of observations rendered convergence of the models difficult. Size and significance of coefficients reduced due to overspecification, but also because random effects take into account the sample selection created by exclusion windows. Devaluation models could not be estimated because the correlation coefficient $r$ was outside the unity radius. For all other estimated models, $r$ was highly significant. This is discernible evidence of random effects in the data and, thus, of inter-temporal heterogeneity. However, it cannot be directly interpreted as multiformity of the underlying structural equations. Overall, economic significations were kept intact. While fit improved over the respective simple probits, signals from prediction are mixed.

\section{F. Specification Tests}

A further novelty of this study is the verification of results with formal specification tests. We employ Wald, LM, LR and modified t-tests appropriate for models with categorical outcomes.

Firstly, we use the Davidson and MacKinnon (1993) t-ratio test of the nonnested hypothesis that our alternative set of variables, $\mathbf{z}_{\mathbf{i}}$, is the appropriate one as a structural equation of the probit model, compared to the set $\mathbf{x}_{\mathbf{i}}$ used in Model 6. We have been unable to validate this hypothesis, despite the improved fit of the alternative specification. Similar results apply to all relevant comparisons. This should be considered as evidence of less-than-acute consistency of all specifications with the observed data, rather than genuine superiority of one over the other.

Next, we construct Chow-type tests of structural breaks for probit models. We examine both the temporal division of the sample to pre- and post-1989 data, as well as the exclusion of "safe haven" countries. In both cases, the restricted model, estimated on the entire pooled data set, is Model 6. The hypothesis of temporal stability was rejected at every plausible significance level. Hence, the domestic and global conditions, which provide the scope for a crisis to erupt and develop, are era-specific. ${ }^{8}$ The hypothesis of cross-sectional stability cannot be rejected. However, this can be merely the effect of mutual cancelling-out, due to the large span of the panel data.

Finally, tests for omitted variables were conducted to evaluate the relevance of

\footnotetext{
${ }^{8}$ Tests are based on the classical assumptions. Despite the -established- presence of heteroskedasticity, Greene (1997, p292) notes that with a reasonably large sample, as in our panel, the test is valid. Anyhow, the actual probability of a type I error in the heteroskedastic case is actually smaller than the chosen significance level.
} 
consistently insignificant regressors, primarily credit and loans to the private sector.. The hypothesis $\mathrm{H}_{0}: \boldsymbol{Q} \beta=\boldsymbol{r}$ of the Wald test was imposed on models employing the full vector of parameters. The hypothesis could not be rejected for any of the models. Therefore, credit and private loans are largely irrelevant and estimators of restricted and unrestricted models are equally consistent and efficient.

\section{Conclusions}

A comprehensive empirical study on currency crises, based on LDV models has been presented. Results show that there are some patterns emerging across specifications, irrespectively of whether involved fundamentals work deterministically or as a co-ordination device for expectations. Money supply, the real exchange rate, the current account, unemployment, a budget deficit and the lack of real growth are the most consistent determinants of crises. Capital controls can deter crises but not if imposed post-factum. Contagion is very important and it complements or even substitutes for domestic imbalances, especially so in more recent crises, occurring in an increasingly inter-related international environment. The main results are quite robust to different model specifications.

Accumulated variables more clearly uncover the causal relationships described by theoretical models, but fail to predict the timing of crises; prominent among them is accumulated appreciation of sufficient size and duration. Inter-temporal heterogeneity and heteroskedasticity were uncovered; taking account of the latter considerably improves performance. However, some sensitivity remains. Modelling factors are partly responsible for that, e.g. the higher frequency, larger panels used, and collinearity among regressors. The rest has to be attributed to the inherent dissimilarity of various episodes, the exchange rate regime upon which they occur, but also the definition of what constitutes a crisis, a fact disguised before. In any case, we cannot conclude that crises present uniformity. Thus, inference, prediction and policy suggestions cannot be globally applicable. Actual devaluations appear more readily explicable and, to a greater degree, predictable, while minor attacks and successful defences are the most difficult to capture empirically and predict.

Although the results obtained with monthly data partially supplement findings of studies utilising data of lower frequency, they present qualitative differences. Most prominent among them are the reversal of the effect of appreciation in contemporaneous and lagged horizons as well as the irrelevance of the credit, wages and private loans variables, both of them being highly significant in studies in lower 
frequency. The proxy for financial boom in particular is a high profile explanation invoked in models of information asymmetries. Its insignificance should be attributed, not only in the noise of the time-series in higher frequency but more structurally to the inapplicability of the moral hazard framework to developed countries. While our knowledge of crisis mechanics is enriched, on average, higher frequency does not offer a comparative advantage to the international investor seeking a timely and verbatim forecast. It is perhaps of greater use to the policy maker, although not in a fashion of early warning signals but rather as an instrument of tracing underlying processes. The multi-dimensionality of the crises-fundamentals relationship means that the general exchange rate strategy should combine corrective measures for fundamentals visibly incompatible with the desired level of the exchange rate and actions aimed in soothing market sentiment, so that crises unjustified by fundamentals could be avoided.

In the context of existing methodologies, it is impossible to ensure that all relevant fundamentals have been correctly modelled. Hence, admission of multiple equilibria and herding behaviour is bound to be suggestive too. However, failure to translate a closer fit of crises with economic and political determinants into an improvement in predictability, shows that crises are not all alike and cannot be treated in a unified manner. Predicting future episodes depends on a judicious choice of the temporal and cross-section spread of the sample. The notion of macroeconomic determinism as the rigid framework of crises seems less appropriate than the effort to detect potential weaknesses that can focus the attention of international markets to a particular economy. The increasing mobility of international capital and its inherent propensity to scrutinise speculative opportunities or hedging necessities, tend to expose and magnify weaknesses that would otherwise be internally solvent. There is every reason to believe that this tendency will be enhanced in the future, especially for emerging markets, where the state of the banking system will be increasingly examined.

\section{Acknowledgements}

We would like to thank Eric Pentecost, Lucio Sarno and Michael Moore for useful comments. Any remaining mistakes are our own responsibility. 


\section{References}

Agenor, P.R., Bhandari J.S., \& Flood R.P. (1992) Speculative Attacks and Models of Balance-of Payments Crises, NBER Working Paper, No 3919, November.

Barro, R. \& Gordon, D. (1983) A Positive Theory of Monetary Policy in a Natural Rate Model, Journal of Political Economy, 91, 589-610.

Berg A. \& Pattillo, C. (1998) Are Currency Crises Predictable? A Test, IMF Working Paper, WP/98/154.

Blanco, H. \& Garber, P.M. (1986) Recurrent Devaluation and Speculative Attacks on the Mexican Peso, Journal of Political Economy, 94, 148-66

Buiter, W., Corsetti, G. \& Pesenti, P. (1996) Financial Markets and International Monetary Co-operation. Cambridge: Cambridge University Press.

Butler, J. \& Moffitt, R. (1982) A computationally Efficient Quadrature Procedure for the One Factor Multinomial Probit Model, Econometrica, 50, 761-764.

Calvo, G. \& Mendoza, E.G. (1997) Rational Herd Behaviour and the Globalisation of Securities Markets, mimeo. University of Maryland, November.

Caplin, A. \& Leahy, J. (1994) Business as Usual, Market Crashes and Wisdom After the Fact, American Economic Review, 84, 548-565.

Cumby, R.E. \& van Wijnbergen, S. (1989) Financial Policy and Speculative Runs with a Crawling Peg: Argentina 1979-81, Journal of International Economics, 27, 11-27.

Davidson, R \& MacKinnon, J.G. (1993) Estimation and Inference in Econometrics. New York, Oxford University Press.

Eichengreen, B., Rose, A.K., \& Wyplosz, C. (1995) Exchange Market Mayhem: The antecedents and Aftermath of Speculative Attacks, Economic Policy, 21, 249-312.

Eichengreen, B., Rose, A.K., \& Wyplosz, C. (1996) Contagious Currency Crises, Scandinavian Journal of Economics, 98, 463-84.

Esquivel, G. \& Larrain, F.B. (1998) Explaining Currency Crises, Harvard Institute for International Development Discussion, Paper no 666, November.

Flood, R.P. \& Garber, P. (1984) Collapsing Exchange Rate Regimes: Some Linear Examples, Journal of International Economics, 17, 1-13.

Flood P.R. \& Marion, N.P. (1998) Perspectives on the Recent Currency Crisis Literature, IMF Working Paper, WP98/130.

Frankel, J. \& Rose, A.K. (1995) An Empirical Characterisation of Nominal Exchange Rates, in Handbook of International Economics 3 (Ed.) G. Grossman, G., Rogoff, K., Amsterdam: North Holland, pp. 1689-1729

Frankel, J.A. \& Rose, A.K. (1996) Currency Crashes in Emerging Markets: An Empirical Treatment, Journal of International Economics, 41, 351-66

Gerlach, S. \& Smets, F. (1995) Contagious Speculative Attacks, European Journal of Political Economy, 11, 90-107.

Girton, L. \& Roper, D. (1977) A Monetary Model of Exchange Market Pressure Applied to Post-war Canadian Experience, American Economic Review, 67, 537-548. 
Goldberg, L.S.(1994) Predicting Exchange Rate Crises:Mexico Revisited, Journal of International Economics, 36, 413-430.

Goldfajn, I.\& Valdes, R. (1997) Are Currency Crises Predictable?, IMF Working Paper, WP/97/159

Greene, W.H. (1997) Econometrics Analysis. New York University, Prentice Hall

Harvey, A. (1976) Estimating Regression Models with Multiplicative Heteroskedasticity, Econometrica, 44, 461-465.

Hotelling, H. (1931) The Economics of Exhaustible Resources, Journal of Political Economy, 39, 137-175.

Jeanne, O. \& Rose, A.K. (1999) Noise Trading and Exchange Rate Regimes, NBER Working Paper, 7104.

Klein, M. \& Marion, M.P. (1997) xplaining the Duration of Exchange-Rate Pegs, Journal of Development Economics, 54, 387-404.

Krugman, P. (1979) A Model of Balance of Payments Crises, Journal of Money, Credit and Banking, 11, 311-325.

Kydland, F. and Prescott E. (1977) Rules Rather than Discretion: The Inconsistency of Optimal Plans, Journal of Political Economy, 85, 473-491.

Meese R.A. \& Rogoff, K. (1983) Empirical Exchange Rate Models of the Seventies: Do They Fit Out-of-sample?, Journal of International Economics, 14, 3-24.

Mishkin, F. (1992) Anatomy of a Financial Crisis, Journal of Evolutionary Economics, 2, 115-130.

Mishkin, F. (1996) Understanding Financial Crises: A Developing Country Perspective, NBER Working Paper, 5600.

Mussa, M. (1979) Empirical Regularities in the Behaviour of Exchange Rates and Theories of the Foreign Exchange Market, Carnegie-Rochester Conference Series On Public Policy, 11, 9

Obstfeld, M. (1994) The Logic of Currency Crises, Cahiers Economiques et Monetaires, 43.

Persaud A.D. (1998) Event Risk Indicator Handbook, Global Foreign Exchange Research: Technical Series, unpublished manuscript.

Rose, A.K. (2001) unpublished comments on Bordo, M.D., Eichengreen, B., Klingebiel, D. \& Martinez-Peria, S. (2001). Is the Crisis Problem Growing More Severe?, Economic Policy, April, pp. 53-82.

Salant, S. \& Henderson, D. (1978) Market Anticipation of Government Policy and the Price of Gold, Journal of Political Economy, 86, 627-48. 